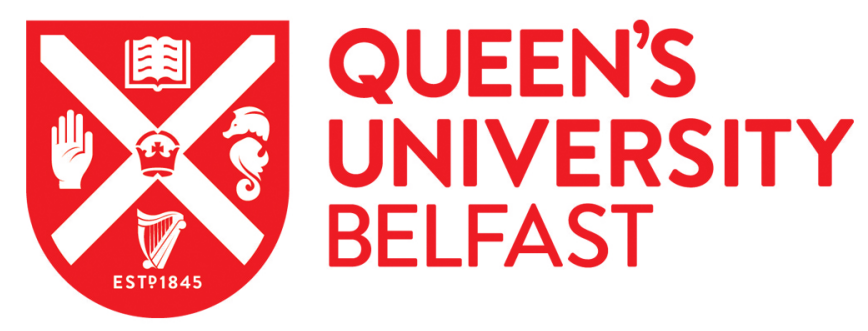

\title{
Inhibition of Microbial Methylation via arsM in the Rhizosphere: Arsenic Speciation in the Soil to Plant Continuum
}

Afroz, H., Su, S., Carey, M., Meharg, A. A., \& Meharg, C. (2019). Inhibition of Microbial Methylation via arsM in the Rhizosphere: Arsenic Speciation in the Soil to Plant Continuum. Environmental Science and Technology, 53(7), 3451. https://doi.org/10.1021/acs.est.8b07008

Published in:

Environmental Science and Technology

Document Version:

Peer reviewed version

Queen's University Belfast - Research Portal:

Link to publication record in Queen's University Belfast Research Portal

Publisher rights

(c) 2019 American Chemical Society. This work is made available online in accordance with the publisher's policies. Please refer to any applicable terms of use of the publisher.

\section{General rights}

Copyright for the publications made accessible via the Queen's University Belfast Research Portal is retained by the author(s) and / or other copyright owners and it is a condition of accessing these publications that users recognise and abide by the legal requirements associated with these rights.

Take down policy

The Research Portal is Queen's institutional repository that provides access to Queen's research output. Every effort has been made to ensure that content in the Research Portal does not infringe any person's rights, or applicable UK laws. If you discover content in the Research Portal that you believe breaches copyright or violates any law, please contact openaccess@qub.ac.uk. 
Characterization of Natural and Affected Environments

\section{Inhibition of Microbial Methylation via arsM in the Rhizosphere: Arsenic Speciation in the Soil to Plant Continuum \\ Hasina Afroz, Shiming Su, Manus Patrick Carey, Andrew A. Meharg, and Caroline Meharg}

Environ. Sci. Technol., Just Accepted Manuscript • DOI: 10.1021/acs.est.8b07008 • Publication Date (Web): 15 Mar 2019

Downloaded from http://pubs.acs.org on March 19, 2019

\section{Just Accepted}

"Just Accepted" manuscripts have been peer-reviewed and accepted for publication. They are posted online prior to technical editing, formatting for publication and author proofing. The American Chemical Society provides "Just Accepted" as a service to the research community to expedite the dissemination of scientific material as soon as possible after acceptance. "Just Accepted" manuscripts appear in full in PDF format accompanied by an HTML abstract. "Just Accepted" manuscripts have been fully peer reviewed, but should not be considered the official version of record. They are citable by the Digital Object Identifier (DOI®). "Just Accepted" is an optional service offered to authors. Therefore, the "Just Accepted" Web site may not include all articles that will be published in the journal. After a manuscript is technically edited and formatted, it will be removed from the "Just Accepted" Web site and published as an ASAP article. Note that technical editing may introduce minor changes to the manuscript text and/or graphics which could affect content, and all legal disclaimers and ethical guidelines that apply to the journal pertain. ACS cannot be held responsible for errors or consequences arising from the use of information contained in these "Just Accepted" manuscripts. 
1 Inhibition of Microbial Methylation via arsM in the Rhizosphere: Arsenic

2 Speciation in the Soil to Plant Continuum

3

4 Hasina Afroz ${ }^{1}$, Shiming Su², Manus Carey ${ }^{1}$, Andy A. Meharg ${ }^{*}, 1$ and Caroline Meharg*,1

5

61 Institute for Global Food Security, Queen's University Belfast, David Keir Building, Malone

7 Road, Belfast, BT9 5BN, UK.

$8 \quad{ }^{2}$ Institute of Environment and Sustainable Development in Agriculture, Chinese Academy of

9 Agricultural Sciences/Key Laboratory of Agro-Environment, Ministry of Agriculture, Beijing, $10 \quad$ P.R. China.

11

12

*Corresponding authors

13

A.A. Meharg, aa.meharg@qub.ac.uk, +44 (0) 2890975413

14

C.Meharg, caroline.meharg@qub.ac.uk, +44 (0) 2890976880

15

16

17

18

19

20

21

22

23

24

25

ACS Paragon Płus Environment 


\section{ABSTRACT}

27 The interplay between rice roots and manuring with respect to arsenic speciation, subsequent

28 assimilation into roots, and translocation to shoots in paddy soil was investigated, alongside

29 bacterial diversity characterization. Planting increased soil Eh and decreased soil solution

30 arsenic species: inorganic arsenic (iAs), monomethylarsonic acid (MMA), trimethylarsenic oxide (TMAO) and dimethylarsinic acid (DMA). Presence of plant roots increased copy number of Clostridium and Tumebacillus 16S rRNA as well as Streptomyces arsenic methylating gene (arsM), but decreased Acidobacteria_GP1 16S rRNA and R. palustris

34 BisB5 arsM. Sum of arsenic species decreased under root influence due to the interplay of 35 inorganic arsenic mobilization in bulk soil under anaerobic and immobilization under oxygenated rhizospheric conditions. Manuring increased all soil solution arsenic species (>90\%), shoot total arsenic (60\%), copy number of Geobacter 16S rRNA and R. palustris TIE-1 ars $M$, indicative of a shift towards microbes with iron reduction and oxidation as well as arsenic methylation capabilities. 


\section{INTRODUCTION}

53 Rice grain is circa. 10-fold elevated in inorganic arsenic, a class-one, non-threshold 54 carcinogen, compared to virtually all other arable crops. ${ }^{1}$ The levels of inorganic arsenic in 55 rice grain is such that they are deemed a threat to human health and have led to legislation to regulate inorganic arsenic's concentrations in rice products by the European Union at 0.2 $\mathrm{mg} / \mathrm{kg}$ As in white rice, ${ }^{2}$ with the WHO setting advisory levels at this concentration. ${ }^{3}$ Young children are considered to be at particular threat and stricter levels have been set at $0.1 \mathrm{mg} / \mathrm{kg}$ of arsenic for rice based baby foods by the European Union ${ }^{2}$ and, at the time of writing, this threshold for rice based baby foods is also under consideration in the USA. ${ }^{4}$ The introduction of food-standards will challenge the food processing industries to produce rice products lower in inorganic arsenic as baby foods currently exceed these standards in circa $50 \%$ of samples tested in the EU. ${ }^{5}$

64

The reason why rice is problematic with respect to inorganic arsenic is simply due to the soil reduced redox conditions that predominate under paddy rice cultivation. ${ }^{6}$ Arsenic, as arsenate, from sources such as the weathering of rocks, builds up in iron (III) oxyhydroxide (iron plaque) that coats soil particles and sediments under aerobic conditions. Under anoxic conditions insoluble iron (III) is reduced to soluble iron (II) and relatively insoluble arsenate $(\mathrm{As}(\mathrm{V}))$ to the more soluble arsenite $(\mathrm{As}(\mathrm{III}))$. It is $\mathrm{As}(\mathrm{V})$ and $\mathrm{As}(\mathrm{III})$ together that are termed "inorganic arsenic", iAs, as they are readily interchangeable depending on prevailing abiotic and biotic conditions. As(V) and As(III) are analogues of the nutrients phosphate and silicic acid, respectively. ${ }^{6}$ Rice has a high demand for both phosphate and is a silicic acid accumulator. ${ }^{7}$ If iAs is available to roots, such as under paddy cultivation, rice will take up 
77

high levels of iAs, to such an extent that rice shoot to soil arsenic concentrations are in the order of $1: 1,{ }^{8}$ remarkable for a non-essential toxicant.

iAs species are not the only forms of arsenic found in rice grain. Dimethylarsinic acid (DMA) can contribute over $50 \%$ of the arsenic concentration in grain, with DMA concentrations in rice being highly variable around the globe. ${ }^{1}$ DMA is not produced in planta ${ }^{9}$ and derives from the methylation of iAs, metabolised by soil bacteria that express $\operatorname{ars} M$ genes, ${ }^{10}$ with subsequent assimilation of DMA by roots. ${ }^{11}$ Although roots are relatively inefficient at assimilating DMA, as compared to arsenate or arsenite, DMA is much more efficiently translocated to grain than iAs species, primarily as it is not as retarded in its progression through the plants vascular system by phytochelatin complexation that iAs species undergo in planta. $^{12}$ Under reducing conditions $\operatorname{ars} M$ catalyses a stepwise conversion of iAs to monomethylarsonic acid (MMA), DMA, trimethylarsenic oxide (TMAO) and finally tetramethylarsonium (TETRA). ${ }^{10}$ All of these species, with the exception of TMAO, can be found in polished rice grain though DMA predominates. ${ }^{13}$

The reason why DMA is variable in rice throughout the globe is not known. Evidence suggests that soil organic matter (SOM), which is a key driver in soil redox has a role with methylated species in soil solution correlating with soluble SOM, and methylation increasing with different organic matter (OM) amendments to soil. ${ }^{14,15}$ The interplay between the rhizosphere and arsenic speciation dynamics also may have a role. Rice aerates its roots through aerenchyma leading to their (partial) coating in iron plaque with subsequent sequestration of arsenic, as both arsenate and arsenite. ${ }^{16-18}$ Bulk soil then acts as a source of labile As(III), which is moved due to advective transpiration-driven forces and via molecular diffusion along a concentration gradient to the root. ${ }^{19-22}$ Microbes expressing ars $M$ genes are 
100 highly diverse in soil and root rhizosphere, both phylogenetically and ecologically, ${ }^{20,23}$ which 101 could have significant role in biogeochemical cycling of arsenic. However, it is not known 102 how the rhizosphere and amendments with OM interplays with arsenic methylation and 103 subsequent assimilation by the roots, and how this varies with soils of differing origin. 104 Planted and unplanted microcosms, with soils sampled across one of the main EU rice 105 growing regions, Valencia, Spain, were monitored through time to investigate methylation of 106 arsenic to further understand the role of the rhizosphere in rice assimilation of arsenic. Here 107 we investigated the arsenic speciation in the soil to shoot continuum with concurrent 108 monitoring of soil bacterial genomic ars $M$ and 16S rRNA copy number through qPCR. 109 Following this, we chose 1 soil to investigate the interaction of planting and manuring, using 110 the same methods plus paired amplicon sequencing ${ }^{24,25}$ of $\operatorname{ars} M$ and 16S rRNA for in depth 111 phylogenetic analysis of arsenic methylating soil microbial communities. 


\section{MATERIALS AND METHODS}

\section{Experimental design}

116 Paddy soils, classified as Entisols, were collected from five different fields across the region 117 of Valencia, Spain, as described and characterized by Signes-Pastor et al., ${ }^{26}$ were used in this 118 study. The location and characteristics of soils are shown in Table S1. Field moist soils were 119 sieved to $<2 \mathrm{~mm}$ before the experiment. Rice seed (IRGA 425) was the plant cultivar used. 120 Before planting, rice seeds were sterilized with $\mathrm{H}_{2} \mathrm{O}_{2}$ and then germinated at $25^{\circ} \mathrm{C}$ for 5 days.

121 Two different microcosm experiments were conducted.

122

123 Experiment 1 (5 soils, planted/unplanted): For the first microcosm experiment field moist soil 124 (for details on soil 1-5 see Table S1) was added to $50 \mathrm{ml}$ centrifuge tubes to an equivalent of 30 g dry weight. Pre-germinated seedlings were planted into half the microcosms resulting in unplanted and planted treatments. In total 90 microcosms ( 5 soils, 2 treatments, 9 time points) were set up to enable 9 destructive harvests at weekly spacing, with each soil represented by one planted and unplanted replicate at each harvest. On planting the microcosms had ultrapure water added to maintain a $2 \mathrm{~cm}$ layer of standing water above the soil surface. Microcosms were then placed into plant growth chambers (Fitotron) with day/night temperature $28^{\circ} \mathrm{C} / 25^{\circ} \mathrm{C}$, light period $16 \mathrm{~h}$ per day. Rice seedlings were harvested weekly, starting at 2 weeks. Rice seedlings were taken out of tubes by shaking the tube and carefully removing the adhering soils. After repeated rinsing with ultra-pure water rice shoot and root were separated and stored at $-20^{\circ} \mathrm{C}$ until subsequent analysis. Once the plant was removed the centrifuge tubes were placed in a centrifuge (Sorvall Legend RT at $4600 \mathrm{rpm}$ ) for 20 minutes, soil porewater decanted and both soil and porewater immediately frozen and stored at $-20^{\circ} \mathrm{C}$ until subsequent analyses. Chemical and molecular analysis (qPCR) from soil, plant and pore water samples was conducted (described below). 
140 Experiment 2 (1 soil, full factorial design, planted/unplanted and manured/non-manured): For

141 the second microcosm experiment soil-5 (see Table S1) was incubated with four treatment

142 combinations and five replicates of each treatment: non-manured unplanted (NMNP), non-

143 manured planted (NMP), manured unplanted (MNP) and manured planted (MP), for 144 molecular and chemical analysis. Bovine farm Yard Manure (FYM) was dried in an oven at $14570^{\circ} \mathrm{C}$ to a constant weight and ground to fine powder. Following this, the total element 146 content of FYM was analysed by X-ray florescence spectrophotometry (XRF). For manure

147 treated microcosms the ground and dried FYM was applied to the soil @ 10\% dry weight 148 basis, and mixed very well before rice seedlings were planted into half of the manured 149 microcosms. Ultra-pure water was added to maintain flooded condition during the incubation. Microcosms were then placed into a plant growth chamber (Fitotron) for 2 weeks using the

151 same growth condition as in microcosm experiment 1. After 2 weeks, samples were collected 152 as described above for experiment 1. Chemical and molecular analysis (qPCR) from soil, plant and pore water samples was conducted as described below. In addition to these, amplicon sequencing of soil DNA to assess the diversity of bacterial ars $M$ and $16 \mathrm{~S}$ rRNA was conducted (described below). The Eh and $\mathrm{pH}$ was measured in planted and non-planted microcosms by inserting an $\mathrm{Eh} / \mathrm{pH}$ meter through the soil surface, with the live plant still in

157 place in the planted microcosm, to a depth of $2 \mathrm{~cm}$ and then waiting for the reading to stabilize before recording that reading.

\section{Arsenic speciation in soil pore water}

161 Arsenic species in 0.4 micron Millipore membrane filtered soil porewaters (iAs, MMA,

162 DMA, TMAO and TETRA) were determined using a Dionex IC chromatographic system 163 interfaced with ICP-MS (ICS-5000 DC, Thermo Scientific) as outlined in detail in Signes- 
164 Pastor et al. ${ }^{5,26}$ Using an arsenic speciation specific IC-column, IC-ICP-MS, unlike HPLC 165 anion exchange - ICP-MS, separates TMAO, and we run authentic TMAO samples, and 166 cross validate with cation exchange IC-ICP-MS ${ }^{27}$. We have added TMAO to the list of 167 analytes detected in soil porewaters. Results were expressed on a per $\mathrm{kg}$ soil $(\mu \mathrm{g} / \mathrm{kg})$ and 168 statistical analysis performed in Minitab as outlined below.

169

$170 \quad$ Plant analysis

171 Plant shoot and root material was digested using concentrated nitric acid microwave 172 digestion, again following protocols outlined in Signes-Pastor et al. for total arsenic 173 (experiment 2) and arsenic species (experiment 1). ${ }^{5,26}$ Statistical analysis was performed in 174 Minitab as outlined below. For further details see the supporting information 1.

175

176 DNA extraction

177 Soil DNA was extracted from $0.5 \mathrm{~g}$ soil from each microcosm using the Powerlyzer ${ }^{\circledR}$ 178 PowersSoil ${ }^{\circledR}$ DNA isolation kit (MOBIO Laboratories, Inc.) following the manufacturer's 179 instructions. For further details see the supporting information 1.

180

\section{Quantitative PCR}

182 Relative bacterial 16S rRNA and ars $M$ copy number were measured on the Eppendorf mastercycler (Realplex ${ }^{4}$, Hamburg, Germany) using precisionPLUS MasterMix premixed with SYBR green (PrimerDesign, USA). Primer pairs of $16 \mathrm{~S} \_1369 \mathrm{~F} / 16 \mathrm{~S} \_1492 \mathrm{R}^{21}$ and $\operatorname{ars} M \mathrm{~F} 1 / \operatorname{ars} M \mathrm{R} 22^{20}$ were used to amplify and quantify the relative copy number of bacterial $16 \mathrm{~S}$ and $\operatorname{ars} M$ genes, respectively. For further details see the supporting information 1. 


\section{Amplicon sequencing and processing of the resultant data}

190 Following quantification, 20 DNA samples extracted from soil of each microcosm of

191 experiment 2, were submitted for 250bp paired end amplicon sequencing of the 16S rRNA

192 (V4 region) and $\operatorname{ars} M$ gene on the Miseq. Initial processing of the data involved adapter

193 trimming ${ }^{28}$ and clipping ${ }^{29}$ followed by quality control analysis using fastqc ${ }^{30}$ and merging of 194 forward and reverse paired reads with fastq-join ${ }^{31}$. For further details see the supporting 195 information 1.

\section{Bioinformatics and statistical analysis of the amplicon sequencing data}

198 Both 16S rRNA and arsM merged sequences were processed using QIIME version $1.8^{32}$ for generation of absolute and relative OTU count-tables, taxonomic assignment and alpha and beta diversity analysis. Quality filtering of both $16 \mathrm{~S}$ rRNA and arsM OTUs involved removal of OTUs with lowest abundance. The arsM OTUs were also filtered to remove any OTUs with $<70 \%$ identity and query coverage to ars $M$ protein sequences (blastx against $\mathrm{nr}$ ), followed by taxonomic annotation based on blastn against bacterial genomes and arsM related sequences downloaded from the fungene database ${ }^{33}$. For 16S rRNA, phyla (level 2) and genera (level 6) showing relative abundance $>1 \%$ were identified, followed by statistical analysis (see section Minitab below). Statistical analysis on the overall arsM OTU and genus level 16S rRNA OTU count tables was performed in $\mathrm{R}$ with DESeq2 using the False Discovery Rate $($ FDR) $<0.05$ and an absolute $\log 2$ foldchange $(\log 2 \mathrm{FC})>1$ as cutoff for significance. Identified significant changes in copy number were assigned to 4 groups: Group I: OTUs with significant plant effect and increased copy number in unplanted soil, Group II:

211 OTUs with significant plant effect and increased copy number in planted soil, Group III:

212 OTUs with significant manure effect and increased copy number in manured soil, Group IV:

213 OTUs with significant manure effect and increased copy number in non-manured soil. OTUs 
within each group were visualised via a heatmap ( $\mathrm{R}$ version 3.2.2, $\mathrm{R}$ package gplots and heatmap2), variance partition analysis ( $\mathrm{R}$ version 3.2.2, $\mathrm{R}$ package variencePartition ${ }^{34}$ ), network analysis (Qiime version $1.8^{32}$, Cytoskape version $3.7^{35}$ ) and for each arsM OTU in Group I-IV the most highly correlated Group I-IV genus level 16S rRNA OTU identified (Spearman's rank correlation, GraphPad Prism version 6.0 for MAC OS). For further details see the supplementary information 1 .

220

221

\section{General linear modelling}

222

Minitab version 16 (Minitab, PA, USA) was used as the statistical platform for the analysis of chemical data, qPCR data and relative count data of abundant phyla and genera. For plant and soil solution speciation data, qPCR and relative count data of abundant phyla and genera (Level 2 and level 6 16S rRNA amplicon data), General Linear Modelling (GLM) was employed. For Eh and $\mathrm{pH}$ measurements the un-paired t-test was used for identification of significant differences. Results were plotted in GraphPad Prism (version 7). For further details see the supporting information.

\section{RESULTS}

\section{Microcosm experiment 1 (5 soils, planted/unplanted)}

The location and properties of the 5 soils used in experiment 1 are presented in Table S1. Soil of origin was significant for all arsenic species soil solution concentrations with the exception of TMAO $(\mathrm{P}>0.05)$, and both $\operatorname{ars} M$ and $16 \mathrm{~S}$ relative copy number varied significantly between soils (Figure S1, Table S2). The iAs was the most variable between soils ranging, on average, 4-fold between soils $(0.2-0.8 \mu \mathrm{g} / \mathrm{kg})$. The soil solution concentrations of all arsenic species were significantly suppressed in the planted microcosms as compared to non-planted microcosms (Figure S1, Table S2). The As species were dominated by iAs and were 
239 suppressed by $>30 \%$ in planted microcosms in all 5 soils (Figure S1). Similar levels of 240 suppression were observed for DMA and TMAO. The greatest suppression of arsenic species 241 in soil solution when comparing unplanted versus planted soil was observed for MMA. 242 Further to that qPCR showed a significant decrease in relative ars $M$ copy number in planted 243 compared to unplanted soils (Figure S1, Table S2).

245 Considering the interaction terms in the statistical model, for planted/unplanted*soil, there was a significant interaction $(\mathrm{p}<0.05)$ for each arsenic species, and for $16 \mathrm{~S}$ rRNA relative copy number $(\mathrm{P}<0.05)$, but not for ars $M$ relative copy number (Table $\mathrm{S} 2)$. This showed that the soils are inherently variable in the way they interact with planting with respect to arsenic speciation, but that the arsM DNA copy number is relatively consistent across soils between the two treatments, i.e. that the treatment was the dominant factor in $\operatorname{ars} M$ copy number as this was highly significant $(\mathrm{P}=0.002)$. Treatment*time interaction for iAs and $16 \mathrm{~S}$ relative copy number were also significant $(\mathrm{P}<0.05)$. Soil*time interactions (Table S2) were significant for iAs, MMA and DMA, indicating that the individual soil microbiology/mineralogy varied with respect to temporal patterns of arsenic release.

Plant biomass production progressed in a linear manner throughout the experiment, positively correlated with time, with root and shoot biomass being similar in quantity (Figure S2). iAs concentrations were over an order of magnitude higher in roots compared to shoots, with roots initially having $100 \mathrm{mg} / \mathrm{kg}$ iAs. The iAs content of both root and shoot declined over time, in shoots more so than roots (Figure S2). Similar magnitudes of differences between roots and shoots were also observed for MMA, though at week 1 MMA was quite high in shoot compared to future time points. MMA concentrations were $\sim 2$-orders of magnitude lower than iAs concentrations, though were similar to DMA concentrations in magnitude, at 
264 least towards the end of the experiment. DMA in shoots was initially higher at week 1, but

265 declined through the experiment, while root concentrations remained consistent (Figure S2).

266 TMAO concentrations in both root and shoot converged at $0.01 \mathrm{mg} / \mathrm{kg}$, 3-orders of 267 magnitude lower than iAs in shoots (Figure S2). The sum of arsenic species in plant tissue 268 (root and shoot) constituted $0.17-1.24 \%$ of arsenic in the microcosms, from week 1 to week 2699 , respectively. Given that root biomass is intimately associated with soil, plant biomass arsenic is only a small sink relative to soil stores.

271

\section{Microcosm experiment 2 (1 soil, planted/unplanted and manured/non-manured)}

273 Soil solution arsenic species analysis and qPCR

274 Soil solution arsenic species concentrations in microcosm experiment 2 were suppressed significantly in planted soil compared to unplanted soil $(\mathrm{P}>0.05)$ (Figure 1, Table S3). The As species were dominated by iAs, which decreased in planted microcosm and increased in response to manure treatment (Figure 1). MMA, DMA and TMAO also decreased in planted microcosm and increased in response to manure treatment (Figure 1). Planting was shown to significantly increase Eh from $-28 \mathrm{mV}$ to $-14 \mathrm{mV}(\mathrm{p}<0.001)$ and decrease $\mathrm{pH}$ from 7.5 to 7.25 $(p<0.001)$ (Figure S3). As in experiment 1 there was a significant decrease in relative arsM copy number in the planted microcosms $(\mathrm{p}=0.001)$, as well as relative $\operatorname{ars} M / 16 \mathrm{~S}(\mathrm{p}=0.002)$, while 16S relative copy number remained unchanged (Figure 1, Table S3).

FYM had significant influence on the soil solution As species concentration and 16S relative copy number (Figure 1, Table S3). In manured soil, the highest concentration was observed for iAs $(0.90 \mu \mathrm{g} / \mathrm{kg}$, mean of manured planted and unplanted) followed by TMAO $(0.90$ $\mu \mathrm{g} / \mathrm{kg}$, mean of manured planted and unplanted $)$ and DMA $(0.54 \mu \mathrm{g} / \mathrm{kg}$, mean of manured 
when compared with non-manured soil. Highest percent increase due to FYM was observed in MMA (from 0.02 mean of non-manure planted and non-manure unplanted) to $0.72 \mu \mathrm{g} / \mathrm{kg}$

291 (mean of manure planted and manure unplanted). Soil ars $M$ relative copy number was not 292 significantly increased by FYM ( $p=0.143$ ) (Figure 1, Table S3). FYM significantly increased the total As concentration in roots by $54 \%$ (from $39.67 \mathrm{mg} / \mathrm{kg}$ to $61.36 \mathrm{mg} / \mathrm{kg}$ ) and in shoots by $60 \%$ (from $0.54 \mathrm{mg} / \mathrm{kg}$ to $0.87 \mathrm{mg} / \mathrm{kg}$ ) (Figure $\mathrm{S} 4$ ). Non-manured plants contained $0.82 \%$ of arsenic in the microcosms, and manured $0.54 \%$ of this figure; again, as for experiment 1 , a small portion of the soil store.

The manure*plant interaction effect was only found to be significant for MMA $(p<0.001)$, with manure-planted soil showing a significantly higher concentration of MMA compared to manured-unplanted soil ( $\mathrm{p}<0.05$, post-hoc multiple comparison test, Minitab) (Figure1, Table S3). There was no significant manure*plant interaction observed for iAs, DMA, TMAO and relative copy number of $\operatorname{ars} M$ and $16 \mathrm{~S}$ rRNA $(\mathrm{p}>0.05)$, indicating that the treatments individually influenced these parameters (Figure 1, Table S3).

\section{Amplicon sequencing of the ars $M$ and 16S rRNA}

Amplicon sequencing of the arsM and 16S rRNA genes was used to investigate soil bacterial community composition and diversity. After paired end joining of reads, a total of $6,733,356$ sequences for the 16S rRNA gene were retained, ranging from 301,26 to 369,822 per sample (Table S4). Rarefaction curves for alpha diversity (diversity within samples) measures (Chao1, Shannon and Simpson) indicated that sequencing depth was sufficient to detect the majority of the 16S rRNA sequence types in all samples (Figure S5A). Significant differences

312 in species richness (Chao1) and diversity (Shannon and Simpson) were observed. Manure

313 addition significantly increased species diversity (Shannon and Simpson, $\mathrm{P}<0.001$, Figure 
$314 \mathrm{~S} 6 \mathrm{~A})$ and species richness (Chao1, $\mathrm{P}<0.01$, Figure S6A). Principle coordinate (PCoA) plots

315 for overall bacterial community diversity between the samples is shown in Figure S7A. The

316 principle component 1 and 2 explained $47.9 \%$ and $15.5 \%$ of the total variation, respectively

317 (Figure S7A) with samples amended with FYM clearly separated from those without FYM

318 and with a less defined level of separation also observed between the unplanted and planted 319 treatments (Figure S7A).

320

321 With respect to $16 \mathrm{~S}$ rRNA analysis in all treatments, Proteobacteria, Acidobacteria, 322 Actinobacteria, Planctomycetes, Chloroflexi, Firmicutes and Bacteriodetes were the 323 dominant phyla constituting $>95 \%$ of total bacterial community and showing relative 324 abundance $>1 \%$ in at least 1 sample (Figure S8A). Among these phyla, Proteobacteria was 325 the most abundant phylum in all treatments. Application of manure significantly increased 326 (GLM, p<0.05, Table S5, Figure S8A) the relative abundance of Proteobacteria, Bacteroides 327 and Firmicutes in both planted and unplanted non-manured treatments, while the 328 Acidobacteria and Chloroflexi significantly decreased (GLM, $p<0.05$, Table S5, Figure S8A).

329 At genus level, there were 17 dominant genera accounting for $>1 \%$ in relative abundance this 330 including OTUs significantly increased in manured (Flavisolibacter, Sphaerobacter, 331 Singulisphaera, Geobacter, Desulfocapsa) and in planted (Nocardiodes, Singulisphaera, 332 Clostridium) soil as well as OTUs significantly increased in non-manured (Caldilinea,

333 Gemmatimona, Defluviicoccus, Thiobacillus, Syntrophobacter, Steroidobacter) and 334 unplanted (Caldilinea, Gemmatimona, Thiobacillus, Syntrophobacter, Steriodibacter) soil 335 (Table S6, Figure S8B). However, with respect to abundant genera, only for Clostridium, 336 Geobacter and Desulfocapsa were the foldchanges shown to be large enough for these to be 337 deemed as significant changes in copy number in response to manure treatment, and/or for 
338 planting during DESeq2 analysis, as the significance threshold for Deseq2 was FDR $<0.05$ and $\log 2 \mathrm{FC}>1$ (Table1, Figure 2A, Table S6).

340

341 For all genus level 16S rRNA OTUs with at least 5 counts in at least 3 samples, the unique

342 and overlapping DESeq2 results for pairwise comparisons are illustrated in the Venn diagram

343 (Figure S9A). Manure effects (130 in total, Group III and Group IV, Figure 2A) showed 115 significant OTUs in planted, 83 significant OTUs in unplanted, with 68 overlapping OTUs. and 41 in manured soil with 1 overlapping OTU. With respect to the 42 significant genus level 16S rRNA OTUs identified for plant effect, 35 of these also showed a significant manure effect (Figure S8A). Hence, only 7 genera level 16S rRNA OTUs responded solely to planting (Group I and Group II, Figure 2A). DESeq2 analysis of genus level 16S rRNA

OTUs, furthermore, showed that the manure treatment resulted in significant $>2$-fold increase $($ FDR $<0.05)$ in copy number of 117 OTUs of specific genera within the phylum Acidobacteria, Actinobacteria, Bacteroidetes, Cyanobacteria, Firmicutes, Proteobacteria and Verrumicrobia (Group III in Figure 2A and Table 1); and 2-fold decrease (FDR $<0.05$ ) in 14 OTUs of another set of genera within the Phylum Acidobacteria, Bacteroidetes, Desulfocapsa, and Geobacter from Group III were also within the list of most abundant

357 (>1\%) genera (Table1, Table S6). Planting resulted in significant $>2$-fold increase $358(\mathrm{FDR}<0.05)$ in copy number of 3 OTUs of genera (Tumebacillus, Clostridium, Desulfotomaculum) within the phylum Firmicutes (Group II in Figure 3A and Table1); and a decrease in 4 OTUs of genera (Acidobacteria_GP1, Dehalogenimonas, Cryptomonadaceae and Alterococcus) within the phylum Acidobacteria, Chloroflexi, Cyanobacteria,

362 Verrumicrobia (Group 1 in Figure 2A and Table1). Of all these, only Clostridium (Group II) 
was also within the list of most abundant ( $>1 \%$ ) genera (Table1, Table S6). Hence 16S rRNA copy number changes of less abundant genera appear to contribute significantly to the overall effect of manure treatment and planting in this study.

The diversity of the ars $M$ gene was also assessed using amplicon sequencing and after paired end joining of reads, a total of 5,690,027 sequences for the ars $M$ rRNA gene were retained, ranging from 210,483 to 609,670 per sample and a median of 274,036 (Table S4). Rarefaction curves for alpha diversity (diversity within samples) measures (Chao1, Shannon and Simpson) indicated that sequencing depth was sufficient to detect the majority of the sequence types in all samples (Figure S5B). Both FYM and planting significantly decreased the $\operatorname{ars} M$ diversity (Shannon and Simpson) (Figure S6B). A significant manure*plant interaction effect was observed for $\operatorname{ars} M$ species richness (Chao1) indicating that planting decreased the overall number of arsM OTUs, in particular in non-manured soil (Figure S6B). PCoA plots of the overall diversity of ars $M$ in different treatments (Figure S6B), shows a clear separation due to manuring and planting, very similar to that observed for $16 \mathrm{~S}$ rRNA diversity. Annotation (blastn against bacterial genomes) of the 2680 representative arsM OTUs that were retained in the filtered OTU table, returned matches for 2104 OTUs against 97 different bacterial genera. Most arsM OTUs showed highest sequence similarity to the genus Rhodopseudomonas (25\%), followed by Roseiarcus (6\%), Gemmatirosa (5\%), Streptomyces (4\%), Thiobacillus (3\%) and Rhodoplanes (2\%); with the rest of the genera matching less that $2 \%$ of these OTUs (Table 2). The most numerous were matches of arsM OTUs to genomes of the species Rhodopseudomonas palustris (638 OTUs) with best matches obtained to 9 different strains within this species: TIE-1 (212 OTUs), BisB5 (180 OTUs), YSC3 (94 OTUs), XCP (69 OTUs), HaA2 (41 OTUs), CGA009 (19 OTUs), DX-1 (8 OTUs), BAL398, (6 OTUs), R1 (9 OTUs). With regards to the genus Rhodopseudomonas, there were 

second-best match (blastn against bacterial genomes) and 120 as best match when using blastn against the fungene_ars $M$ database $\mathrm{d}^{33}$.

For all significant arsM OTUs, the unique and overlapping DESeq2 results for pairwise comparisons are illustrated in the Venn diagram (Figure S9B). Manure effects (319 in total) showed 258 significant OTUs in planted soil and 222 significant OTUs in unplanted soil, with 162 overlapping OTUs. Compared to this, plant effects (73 in total) showed 46 significant OTUs in non-manured soil and 34 in manured soil with 7 overlapping OTUs. With respect to the 73 significant OTUs identified for the plant effect, 12 of these also showed a significant manure effect (Figure S9B).

400

401

Corresponding arsM and genus level 16S rRNA OTUs for 4 identified significant copy 402 number patterns were identified. These are visualized in a heatmap in Figure 2A (genus level 16S rRNA) and Figure 2B (arsM OTUs). For arsM OTUs 29 were assigned to Group I, 32 to Group II, 256 to Group III and 57 to Group IV. For genus level 16S rRNA, OTUs belonging to Group I, II, III and IV are summarized in Table 1. While overall species richness (number) of ars $M$ OTUs was decreased in response to planting and manuring, the largest number of 407 arsM OTUs with significantly changed copy number were observed in Group III (Figure 2B).

408 With respect to annotation of significant ars $M$ OTUs, blastn against bacterial genomes 409 showed the following: Most Group 1 ars M OTUs showed closest sequence similarity to $R$. 410 palustris BisB5 (41\%) followed by R. palustris YSC3 (10\%). Group 2 arsM OTUs showed 411 closest sequence similarity to Streptomyces aurantiacus (12\%) followed by R. palustris TIE4121 (9\%). Group 3 arsM OTUs showed closest sequence similarity to $R$. palustris TIE-1 (29\%) 
and Roseiarcus fermentans (46\%) (88\% of the latter returned as second-best genome match

414 also $R$. palustris TIE-1), followed by Thioalbus denitrificans (3\%). Group 4 arsM OTUs showed closest sequence similarity to $R$. palustris TIE-1 (16\%) and Gemmatirosa kalamazoonesis (11\%) followed by R. palustris BisB5 (7\%). Hence with respect to

417 predominant ars $M$ copy number changes, manuring resulted mainly in increase of $R$.

418 fermentans (blast against the fungene-ars $M$ database ${ }^{33}$ returns for $85 \%$ of these $R$. palustris TIE-1) and R. palustris TIE-1, while planting resulted in decrease of R. palustris BisB5 and increase in S. aurantiacus annotated OTUs. For further details see Table $2 \&$ Supporting information File 2.

423 Variance partition analysis for Group I and II 16S rRNA OTUs verified that $60 \%$ of the variation in Acidobacteria_GP1 copy number was due to planting, while for the other 6 OTUs in Group I and II this was around 20-35\% (Figure 3). For Group I and II arsM OTUs, this analysis verified that $45 \%$ of the variation in copy number was due to planting (Figure 427 S10). Variance partition analysis for Group III and IV 16S rRNA OTUs showed that 28\% and 428 for Group III and IV arsM OTUs that $25 \%$ of the variation in copy number was due the manure effect (Figure S11 and Figure S12).

430

431 With regards to significant correlation (Spearman's rank correlation, $\mathrm{P}<0.05$ ) of copy number 432 patterns between genus level 16S rRNA and arsM OTUs the following results were obtained. 433 Of the 29 arsM OTUs in Group I, 100\% correlated with at least 1 Group I genus level 16S rRNA OTU. Of these 97\% correlated most strongly with Acidobacteria_GP1 and 3\% with Dehaligenimonas (Table S7). Of the 32 arsM OTUs in Group II, 65\% correlated with at least 4361 Group II genus level $16 \mathrm{~S}$ rRNA OTU. Of these $34 \%$ correlated most strongly with 437 Clostridium and 31\% with Tumebacillus (Table S8). All Group III arsM OTUs correlated 
highly significantly with multiple Group III genus level 16S rRNA OTUs. Of these, highest number of arsM OTUs (9\%) correlated most significantly with Luteolibacter (phylum Verrucomicrobia), followed by Devosia (7\%), and Herbaspirillum (6\%) (phylum

Proteobacteria). The rest of the Group III arsM OTUs correlated most significantly to a 442 highly diverse range of genus level 16S rRNA OTUs (Table S9) within the phyla 443 Proteobacteria (25 genera), Firmicutes (21 genera, this including Pseudomonas), 444 Bacteroidetes (5 genera), Acidobacteria (Geothrix) and Actinobacteria (Thermobifida). All 445 Group IV arsM OTUs correlated with at least one Group IV genus level 16S rRNA OTU. Of these 23\% correlated most significantly with Acidobacteria_Gp25, 14\% with Terrimonas, 12\% with Acidobacteria_GP22, 11\% with Streptophyta and 11\% with Tepidibacter (Table 448 S10).

Network analysis plots for genus level 16S rRNA OTUs that responded to planting (Group I and II) are shown in Figure 4A-G. The network for Acidobacteria_GP1 (Figure 4A) shows the strongest connection to all unplanted samples (Group I), due to higher copy number in unplanted soil and was also most highly correlated to Group I arsM OTUs (Table S7). In a similar manner Tumebacillus and Clostridium (Figure 4E and 4F), show the strongest connections to all planted samples (Group II), due to higher copy number in planted soil and these were also most highly correlated to Group II arsM OTUs (Table S8). Network analysis

457 plots for genus level 16S rRNA OTUs that responded to manuring are shown in Figure S13. 458 Individual networks are shown for those Group IV genus level 16S rRNA OTUs (Figure 459 S13A-E) that showed highest levels of correlation with Group IV arsM OTUs (Table S10), with Acidobacteria_GP25 (Figure S13A), Terrimonas (Figure S13B), Acidobacteria_GP22 461 (Figure S13C), Streptophyta (Figure S13D), Tepidobacter (Figure S13E) all showing 462 strongest connections to non-manured samples, due to higher copy number in non-manured 
soil, but with this effect clearly most pronounced for Acidobacteria_GP22 (Figure S13A).

464

465

466

467

468

469

470

471

472

473

474

475

476

477

478

479

480

481

482

483

484

485

486

487

Acidobacteria_GP22 were also shown to be the most highly correlated to Group IV arsM OTUs (Table S10). For Group III genus level 16S rRNA OTUs the overall network shows a clear separation of manure and non-manure samples (Figure S13F), the same applies to networks for Group III and Group IV arsM OTUs (Figure 14A and 14B). Contrary to that, network analysis plots for arsM OTUs that responded to planting (Group I and Group II) show clear separation of planted versus unplanted samples (Figure S15A and S15B). Hence these results provide further evidence of treatment effects and present potential targets for the study of $\operatorname{ars} M$ and microbial arsenic methylation efficiency in paddy soil.

\section{DISCUSSION}

Microbial driven methylation, and potential subsequent volatilization, mediated by ars $M$ plays a crucial role in biogeochemical cycling of arsenic. ${ }^{36}$ Previous studies on ars $M$ diversity in natural rice paddy microbial communities have used low throughput cloning and Sanger sequencing, ${ }^{20,23,36}$ or have limited Illumina sequencing of $\operatorname{ars} M$ amplicons to the study of enrichment cultures from paddy soil ${ }^{37}$, or metagenomics analysis to characterize arsenic metabolizing genes in 5 soils $^{38}$. Our study provides a step-change as it employs arsenic speciation characterization combined with qPCR and high throughput Illumina amplicon sequencing (16S rRNA and arsM gene) to study arsenic mobilization and transformation in response to planting and manuring, alongside detailed analysis of the diversity of complex natural bacterial arsenic transforming communities in rice paddy soil.

Phylogenetic annotation based on the protein coding functional gene ars $M$, may provide additional information as well as a higher taxonomic resolution compared to the wellestablished 16S rRNA gene-based analysis, but is limited by the number of curated arsM 
488 protein sequences in the database ${ }^{33}$. Correlated $16 \mathrm{~S}$ rRNA and ars $M$ gene copy numbers 489 provide complementary information to highlight organisms that may promote arsenic 490 methylation in paddy soil. The ars $M$ based amplicon sequencing analysis revealed a great 491 level of arsM sequence diversity with highest number of top matches against phototrophic 492 purple non-sulfur bacteria of the genus Rhodopseudomonas. These were dominated by strain $493 R$. palustris TIE-1 with smaller numbers of arsM OTUs showing matches to $R$. palustris 494 strains BisB5, YSC3, XCP, HaA2, CGA009 and DX1. High frequency of R. palustris arsM sequences in rice paddy soil has previously been reported ${ }^{38}$. The $R$. palustris ars $M$ gene has been proven to methylate As(III) to the relatively nontoxic pentavalent species DMA(V) and TMAO and confer arsenic resistance to an arsenic sensitive Escherichia coli $\operatorname{strain}^{10}$. Further to that, members of this species have been proposed, based on their As detoxification mechanisms, for bioremediation of arsenic contaminated areas surrounding mines as have been shown to be able to oxidise As(III) to As (V) ${ }^{39}$. Members of this species can grow with or without light or oxygen, fix nitrogen and degrade a wide range of organic compounds,

502 with different strains shown to harbour strain specific genes and exhibit distinctive 503 physiological characteristics with respect to anaerobic fermentation, expanded biodegradation, or expanded light-harvesting capabilities ${ }^{40,41}$ leading to the proposal that they should be reclassified into different species ${ }^{42}$. Hence, differences in copy number of these strains due to plant and manure induced changes in redox potential, $\mathrm{pH}$ and available carbon sources is of considerable interest in the context of arsenic in rice grain.

509 FYM increased all present arsenic species including methylated species in paddy soil solution and with respect to ars $M$ gene OTUs led to significant increase in copy number of large

511 numbers of $R$. fermentans and $R$. palustris TIE- 1 annotated OTUs, with $R$. fermentans 512 reported to grow best under micro-oxic conditions by means of fermentation of sugars and 
513 organic acids ${ }^{43}$ and $R$. palustris TIE-1 shown to be able to grow on a wide variety of carbon

514 sources as well as perform phototrophic Fe(II) oxidation ${ }^{44,45,46}$. It is important to note in this

515 context that $R$. fermentans annotated arsM OTU sequences (genome match), also showed

516 high similarity to $R$. plaustris TIE-1. Further to that, 16S rRNA amplicon sequencing showed

517 manure induced increase in Geobacter, an anaerobe shown to perform anaerobic oxidation of

518 aromatic hydrocarbons to carbon dioxide via reduction of $\mathrm{Fe}(\mathrm{III})^{47,48}$ as well as thought to be

519 capable of nitrate dependent $\mathrm{Fe}(\mathrm{II})$ oxidation $^{49}$. Hence, manuring appears to stimulate

520 microbes involved in arsenic methylation as well as in both iron plaque formation (Fe(II)

521 oxidation) and degradation (Fe(III) reduction), leading to binding and release of arsenic from

522 Fe-plaque around roots. ${ }^{22,50}$

523

524 Higher redox potential of rhizosphere due to oxygenation from rice roots led to suppression of all present arsenic species, including methylated species. This corresponded to decreased arsM copy number (qPCR), species richness (amplicon sequencing, Chao1) and diversity 527 (amplicon sequencing, Simpson, Shannon). This implies that in our study, the number of ars $M$ organisms decreased in planted soil. With respect to Rhodopseudomonas annotated ars $M$ OTUs, some with highest sequence similarity to $R$. palustris BisB5 were suppressed by planting. R. palustris strain BisB5 was shown to contain a gene cluster for anaerobic phenylacetate degradation and was proposed to be best adapted to degradation of plant

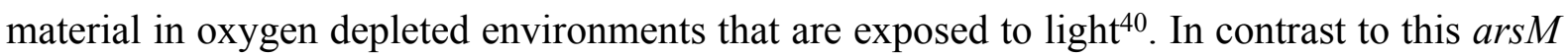

533 OTUs with closest match against S. aurantiacus were increased in planted soil. Streptomyces are generally aerobic bacteria and isolates from rice paddies have been shown to contribute to better growth of rice plants as well as increased levels of arsenic methylation and uptake of DMA into rice shoots ${ }^{51}$. Change in redox potential may therefore play a role in the observed copy number changes of these organisms in response to planting. In our study, the fact that 
rhizosphere soils have lower methylated arsenic species than bulk soil coupled with decrease and shift in ars $M$ organisms could be attributable to oxygenation of the rhizosphere by the root, as radial oxygen loss (ROL), regulates rice rhizosphere $E$ h, ${ }^{52}$ and subsequent

541 assimilation of arsenic ${ }^{18}$. However, total arsenic species, inorganic as well as methylated, 542 decreased in the rhizosphere suggesting that redox, while part of the answer, does not fully explain the reduction in methylated species.

545 The root itself is a sink for all arsenic species, but rates of MMA and DMA accumulation by 546 rice roots are low with much higher rates of arsenate and arsenite assimilation. ${ }^{11}$ Thus, if the 547 root was acting as a major sink, to the extent that they affect soil solution concentrations, then 548 it may be expected that iAs species are preferentially depleted. This was not the case here.

549 Rather than the root tissue, per se, being the sink for arsenic species that leads to the lowering of these species in porewater, it may be associated iron plaque in the rhizosphere. Iron plaque

551 preferentially binds arsenate to arsenite, but has a high capacity to sorb both species, and 552 methylated species. ${ }^{17}$ It is interesting that our ars $M$ amplicon data indicates increase in 553 bacteria with arsenic methylation and $\mathrm{Fe}(\mathrm{II})$ oxidation and $\mathrm{Fe}$ (III) reduction capacity in manured soil, as this could lead to formation of iron plaques and subsequent release of arsenic from iron plaque. ${ }^{44-50,18}$ As well as the root potentially creating new sinks for arsenic species, iron plaque and root tissue, the enhanced oxygenation of the planted microcosms

557 here may have led to lower mobilization of iAs from sediment stores as it is reducing 558 conditions that drive this mobilization. ${ }^{19,22}$ Lower mobilization of iAs would mean lower substrate for methylation and, hence, lower production of methylated arsenic species.

561 A number of studies have considered arsenic species mobility in the rhizosphere. ${ }^{20,21}$ The 562 current study differs from these in that it compares planted versus non-planted microcosms, 
563

564

565

566

567

568

569

570

571

572

573

574

575

576

577

578

579

580

581

582

583

584

585

586

587

while the other studies sampled a rhizosphere continuum from bulk soil to root surface. The studies of Jia et al..$^{20,21}$ did not show the inhibition of in culture medium solution of arsenic species concentration in the rhizosphere. In essence these studies have a relatively small and constrained rhizosphere, to enable spatial sampling, with the root-soil interface surrounded by a large volume of bulk soil to resupply arsenic species if they become depleted in the rhizosphere. In the field, particularly in densely planted agronomic systems, the rhizosphere can be considered as a continuum, with dense and overlapping roots. ${ }^{53}$ In our experiments the soil:fresh root biomass ratio was considerable, being 150:1 at week 2 when Eh measurements were made. Even at these low biomass ratios the presence of the root had a profound effect on both Eh and arsenic speciation.

Here, the detailed reporting of arsenic species in both roots and shoots over a time course illustrates, again, that while iAs concentrations in planta are higher than methylated species, it is the methylated species that are more readily translocated to the shoot. ${ }^{12}$ The root measurements do not distinguish between surface plaque bound and species actually assimilated into plant tissues and this must be born in mind when interpreting the data as plaque in roots can have high arsenic concentrations. ${ }^{6}$ Here, the shoot measurements are free from such qualifications and only represent arsenic species assimilated by root and then translocated to shoot. Hydroponic experiments have shown that although iAs species are more efficiently assimilated by the root, ${ }^{11}$ their translocation to shoot are retarded as compared to methylated species, with MMA less effectively translocated to the shoot from roots than DMA. ${ }^{12}$ Arsenate is reduced to arsenite in plant cells and then phytochelatin (PC) complexed, with arsenite-PC complexes then transported into vacuoles via $\mathrm{ABC}$ transporters. ${ }^{6}$ MMA can be thiol complexed, though less efficiently than arsenite, while DMA has lower affinity for thiol complexation, ${ }^{12,54}$ with the affinity to PCs explaining their 
588 relative efficiency in translocation to the shoot. ${ }^{12}$ This pattern can also be seen here, with the addition of TMAO which shows equivalency between root and shoot in concentration, indicating further that increasing methylation leads to enhanced translocation to the shoot. Although not tested, to date, it is likely that TMAO has poor affinity to plant thiols.

593 Most studies use anion exchange HPLC-ICP-MS to speciate arsenic, where TMAO elutes on the solvent front. ${ }^{13}$ As we used the more discriminatory IC-ICP-MS, TMAO was readily detected and quantified. Even though iAs's movement is retarded through the plant, because initial starting concentrations in soil solution and root tissues are much higher, shoot concentrations were circa. 100-fold higher than for MMA, DMA and TMAO. However, in rice grain only iAs and DMA are found in significant quantities, with DMA in many regions of the world reaching equivalency with iAs or exceeding in cases. ${ }^{1}$ Traces of MMA can be found routinely, and TETRA in very elevated grain samples, but interestingly not TMAO. ${ }^{13}$ The differences in grain unloading of DMA and iAs have been studied for rice, ${ }^{55}$ but MMA, TMAO and TETRA not. It is clear that we still have a way to go in understanding the physiology of all arsenic species found in rice with respect to uptake and translocation.

As in previous studies in paddy soil, ${ }^{20,23,36-38,56}$ high diversity of bacterial $16 \mathrm{~S}$ rRNA and $\operatorname{ars} M$ were observed, and shown to be affected by soil amendments. Recent studies on ars $M$

607 have identified high levels of diversity with Proteobacteria, Gemmatmonadales and 608 Firmicutes ${ }^{36}$ as the most common bacterial communities in paddy soil, this including high 609 frequency of $R$. palustris ${ }^{38}$ and many phylogenetically divergent microbes have been shown to harbor the $\operatorname{ars} M$ gene and to be able to convert aqueous iAs to methylated species $^{37}$. Pure

611 culture studies have, furthermore, shown that microbes vary with respect to their methylation

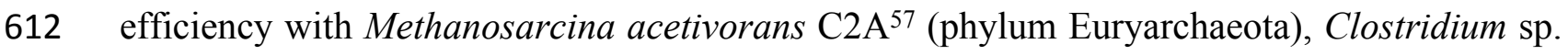


$613 \mathrm{BXM}^{58}$ (phylum Firmicutes) shown to transform 10\%, while Streptomyces sp. ${ }^{59}$ (phylum

614 Actinomycete), Pseudomonas alcaligenes ${ }^{60}$ (phylum Proteobacteria) and Arsenicibacter

615 rosenit $^{61}$ (phylum Bacteriodetes) shown to transform more than $50 \%$ of aqueous iAs to

616 methylated species. In addition our observed correlated ars $M$ and 16S rRNA copy numbers

617 are worth further investigation. The copy number of many Group II arsM OTUs was for

618 example correlated to 16S rRNA Clostridium OTUs, which is interesting as co-culture of $R$.

619 palustris and Clostridium has previously been shown to lead to increased hydrogen

620 production and $R$. palustris genes involved in organic compound catabolism and nitrogen

621 fixation ${ }^{62}$. The copy number of Group III arsM OTUs on the other hand showed correlation

622 to a very diverse range of genus level 16S rRNA OTUs, with highest matches to

623 Luteolibacter and Devosia. Luteolibacter have previously reported as one of the 5 most

624 abundant genera in arsenic contaminated soil ${ }^{63}$ and Devosia were shown to exhibit high

625 sequence similarity to arsenic tolerant organisms isolated from arsenic rich environments ${ }^{64}$.

626 Therefore, both the genomic matches of arsM OTUs and the correlated copy number patterns

627 in Group I, II, III and IV arsM and genera level 16S rRNA OTUs present potential targets for

628 identification of ars $M$ organisms and the study of arsenic transformation in paddy soil.

629

630 The relative ars $M$ copy number is known to be variable between soils, ${ }^{20,23,36-38,56}$ and we have

631 shown this again in the current findings, with highly significant differences also observed

632 between planted and unplanted microcosms. Similarly, arsenic speciation was profoundly

633 influenced by soil origin, planting and manuring. Inherent variation in DMA in soil solution

634 has been shown in other studies, ${ }^{15}$ and the results shown here illustrate that this chemical is

635 spatially and temporally variable in soils, interacting with environmental factors.

636 Environmental factors such as soil solution soluble OM was found to correlate well with

637 DMA in soil solution. ${ }^{15}$ As plants obtain all their DMA from soil solution, ${ }^{9}$ DMA variability 
638 in soil solution will be reflected in root uptake, and ultimately in grain DMA concentrations. ${ }^{1}$ 639 As DMA is less toxic than iAs to humans, altering grain arsenic through paddy soil 640 management can lead to higher DMA to iAs, but some caution is required before promoting 641 soils microbes to convert iAs to DMA. For example, SOM, while promoting arsenic 642 methylation in paddy soils also liberates more arsenic in general leading to enhanced plant 643 uptake to both inorganic and organic species. ${ }^{14}$ Also, while less toxic to humans, DMA is 644 strongly implicated in "straight-head" disease of rice where yield is greatly lowered by DMA 645 (and MMA) exposure due to introducing sterility. ${ }^{23,65}$ It is clear if rice is to be managed to 646 lower grain iAs content then caution needs to be heeded to ensure that adverse consequences 647 are negated. Understanding that the rhizosphere environment greatly alters arsenic 648 concentrations and speciation is a step forward in developing strategies for minimizing grain 649 iAs content without impacting yield. Further studies need to be conducted in a wide range of 650 paddy soils to validate the role of rhizosphere interactions, including microbial mediated arsenic methylation as well as $\mathrm{Fe}(\mathrm{II})$ oxidation and $\mathrm{Fe}(\mathrm{III})$ reduction and its effect on arsenic

652 bound to iron-plaque, and how these can be manipulated to minimize iAs in rice grain.

653

\section{ACKNOWLEDGEMENTS}

655 We thank the Commonwealth Scholarships for funding Hasina Afroz' Ph.D. studentship.

656 Illumina Sequencing was performed by the Centre Of Genomics Research, Institute of 657 Integrative Biology University of Liverpool, Crown Street Liverpool L69 7ZB, UK.

\section{SUPPORTING INFORMATION.}

660 SupportingInformation1.docx (SI1.docx): additional information on materials and methods, 661 additional results in form of 10 tables and 15 figures, relevant references. 
663 Group2, Group3 and Group4 arsM OTUs including, sequence, blast results and most highly 664 correlating 16S rRNA OTU.

665

666

667

668

669

670

671

672

673

674

675

676

677

678

679

680

681

682

683

684

685

686

687 


\section{REFERENCES}

689 (1) Meharg, A. A.; Williams, P. N.; Adomako, E.; Lawgali, Y. Y.; Deacon, C.; Villada, A.; 690 Cambell, R. C. J.; Sun, G.; Zhu, Y. G.; Feldmann, J.; Raab, A.; Zhao, F. J.; Islam, R.; 691 Hossain, S.; Yanai, J. Geographical variation in total and inorganic arsenic content of 692 polished (white) rice. Environ. Sci. Technol. 2009, 43 (5), 1612-1617.

693

694

(2) EU Commission Regulation 2015/1006 of 25 June 2015 amending Regulation (EC) No 695 1881/2006 as regards maximum levels of inorganic arsenic in foodstuffs. 2015. http://eur696 lex.europa.eu/legal-content/EN/TXT/?uri=uriserv\%3AOJ.L_.2015.161.01.0014.01.ENG.

697

698

(3) WHO, 2014. Codex alimentarius commission. Project document proposal for new work 699 on a maximum level for arsenic in rice. $\mathbf{2 0 1 4}$

700 $\mathrm{ftp}$ //ftp.fao.org/codex/meetings/CCCF/cccf5/CRDs/CRD\%2024\%20ARSENIC\%20IN\%20R

701 ICE.pdf

702

703

(4) FDA, 2016. FDA proposes limit for inorganic arsenic in infant rice cereal.

704

http://www.fda.gov/NewsEvents/Newsroom/PressAnnouncements/ucm493740.htm

705

706 (5) Signes-Pastor, A. J.; Carey, M.; Meharg, A. A. Inorganic arsenic in rice-based products 707 for infants and young children. Food Chem. 2016a, 191, 128-134.

708

709

(6) Meharg, A. A.; Zhao, F. J. Arsenic \& Rice; Springer, The Netherlands, 2012.

710

711 (7) Meharg, C.; Meharg, A. A. Silicon, the silver-bullet for mitigating biotic and abiotic 712 stress, and improving grain quality, in rice. Environ. Exp. Bot. 2015, 120, 8-17. 
714 8. Williams, P. N.; Villada, A.; Deacon, C.; Raab, A.; Figuerola, J.; Green, A. J.; Feldmann,

715 J.; Meharg, A. A. Greatly enhanced arsenic shoot assimilation in rice leads to elevated grain 716 levels compared to wheat and barley. Environ. Sci. Technol. 2007, 41 (19), 6854-6859.

717

718 (9) Lomax, C.; Liu, W. J.; Wu, L.; Xue, K.; Xiong, J.; Zhou, J.; McGrath, S. P.; Meharg, A.

719 A.; Miller, A. J.; Zhao, F. J. Methylated arsenic species in plants originate from soil

720 microorganisms. New. Phytol. 2012, 193 (3), 665-672.

721

722 (10) Qin, J.; Rosen, B. P.; Zhang, Y.; Wang, G. J.; Franke, S.; Rensing, C. Arsenic

723 detoxification and evolution of trimethylarsine gas by a microbial arsenite S-

724

adenosylmethionine methyltransferase. Proc. Natl. Acad. Sci., U. S. A. 2006, 103 (7),

725

2075-2080.

726

727 (11) Abedin, M. J.; Cresser, M. S.; Meharg, A. A.; Feldmann, J.; Cotter-Howells, J. Arsenic accumulation and metabolism in rice (Oryza sativa L.). Environ. Sci. Technol. 2002, 36 (5),

729 $962-968$.

730

731

(12) Raab, A.; Williams, P. N.; Meharg, A.; Feldmann, J. Uptake and translocation of inorganic and methylated arsenic species by plants. Environ. Chem. 2007, 4 (3), 197-203.

(13) Hansen, H. R.; Raab, A.; Price, A. H.; Duan, G. L.; Zhu, Y. G.; Norton, G. J.; Feldmann, content. J. Environ. Monit. 2011, 13 (1), 32-34. 
738

739

740

741

742

743

744

745

746

747

748

749

750

751

752

753

754

755

756

757

758

759

760

761

762

(14) Norton, G. J.; Adamoko, E.; Deacon, C.; Carey, A. M.; Price, A. H.; Meharg, A. A.. Effect of organic matter amendment, arsenic amendment and water management regime on rice grain arsenic species. Environ. Poll. 2013, 177, 38-47.

(15) Williams, P. N.; Zhang, H.; Davison, W.; Meharg, A. A.; Hossain, M.; Norton, G. J.; Brammer, H.; Islam, M. R. Organic Matter-Solid Phase Interactions Are Critical for Predicting Arsenic Release and Plant Uptake in Bangladesh Paddy Soils. Environ. Sci. Technol. 2011, 45 (14), 6080-6087.

(16) Liu, W. J.; Zhu, Y. G.; Smith, F. A.; Smith, S.E. Do iron plaque and genotypes affect arsenate uptake and translocation by rice seedlings (Oryza sativa L.) grown in solution culture? J. Exp. Bot. 2004, 55 (403), 1707-1713.

(17) Liu, W. J.; Zhu, Y. G.; Hu, Y.; Williams, P. N.; Gault, A. G.; Meharg, A. A.; Charnock, J. M.; Smith, F. A. Arsenic sequestration in iron plaque, its accumulation and speciation in mature rice plants (Oryza sativa L.). Environ. Sci. Technol. 2006, 40 (18), 5730-5736.

(18) Mei, X. Q.; Wong, M. H.; Yang, Y.; Dong, J. Y.; Qiu, R. L.; Ye, Z. H. The effects of radial oxygen loss on arsenic tolerance and uptake in rice and on its rhizosphere. Environ. Poll. 2012, 165, 109-117.

(19) Bravin, M. N.; Travassac, F.; Le Floch, M.; Hinsinger, P.; Garnier, J.M. Oxygen input controls the spatial and temporal dynamics of arsenic at the surface of a flooded paddy soil and in the rhizosphere of lowland rice (Oryza sativa L.): a microcosm study. Plant Soil 2008, $312(1-2), 207-218$. 
764

765

766

767

768

769

770

771

772

773

774

775

776

777

778

779

780

781

782

783

784

785

786

787

(20) Jia, Y.; Huang, H.; Zhong, M.; Wang, F. H.; Zhang, L. M.; Zhu, Y. G. Microbial arsenic methylation in soil and rice rhizosphere. Environ. Sci. Technol. 2013, 47 (7), 3141-3148.

(21) Jia, Y.; Huang, H.; Chen, Z.; Zhu, Y. G. Arsenic uptake by rice is influenced by microbe-mediated arsenic redox changes in the rhizosphere. Environ. Sci. Technol. 2014, 48 (2), 1001-1007.

(22) Williams, P. N.; Santner, J.; Larsen, M.; Lehto, N. J.; Oburger, E.; Wenzel, W.; Glud, R. N.; Davison, W.; Zhang, H. Localized Flux Maxima of Arsenic, Lead, and Iron around Root Apices in Flooded Lowland Rice. Environ. Sci. Technol. 2014, 48 (15), 8498-8506.

(23) Zhao, F. J.; Harris, E.; Yan, J.; Ma, J.; Wu, L.; Liu, W. J.; McGrath, S. P.; Zhou, J. Z.; Zhu, Y. G. Arsenic methylation in soils and its relationship with microbial arsM abundance and diversity, and As speciation in rice. Environ. Sci. Technol. 2013, 47 (13), 7147-7154.

(24) Caporaso, J. G.; Lauber, C. L.; Walters, W. A.; Berg-Lyons, D.; Huntley, J.; Fierer, N.; Owens, S.M.; Betley, J.; Fraser, L.; Bauer, M.; Gormley, N.; Gilbert, J. A.; Smith, G.;

Knight, R. Ultra-high-throughput microbial community analysis on the Illumina HiSeq and MiSeq platforms. Isme Journal 2012, 6 (8), 1621-1624.

(25) Degnan, P. H.; Ochman, H. Illumina-based analysis of microbial community diversity. Isme Journal 2012, 6 (1), 183-194.

(26) Signes-Pastor, A.J.; Carey, M.; Carbonell-Barrachina, A.A.; Moreno-Jimenez, E.; Green, 
788 A.J.; Meharg, A.A. Geographical variation in inorganic arsenic in paddy soils and rice from 789 the Iberian Peninsula. Food Chem. 2016b, 202, 356-363.

790

791

(27) Savage, L.S. Carey, M. Hossain, M.; Islam, M.R.; de Silva P.MC.S.; Williams, P.N.;

Meharg, A.A. Elevated trimethylarsine oxide and inorganic arsenic in northern hemisphere

793

summer monsoonal wet deposition. Environ. Sci. Technol. 2017, 51, 12210-12218 .

794

795

(28) Martin, M. Cutadapt removes adapter sequences from high-throughput sequencing reads.

EMBnet. J. 2011, 17, 10-12.

797

798

(29) Joshi, N. A.; Fass, J. N. Sickle: A sliding-window, adaptive, quality-based trimming tool 799 for FastQ files (Version 1.33). 2011. Available at https://github.com/najoshi/sickle.

800

801

(30) Andrews, S. FastQC: a quality control tool for high throughput sequence data. 2010.

802 Available online at: http://www.bioinformatics.babraham.ac.uk/projects/fastqc

803

804

(31) Aronesty, E. ea-utils: "Command-line tools for processing biological sequencing data.

805

2011. Available online at: http://code.google.com/p/ea-utils

806

807 (32) Caporaso, J. G.; Kuczynski, J.; Stombaugh, J.; Bittinger, K.; Bushman, F.D.; Costello, E.

808 K.; Fierer, N.; Pena, A.G.; Goodrich, J. K.; Gordon, J. I.; Huttley, G. A.; Kelley, S. T.;

809 Knights, D.; Koenig, J. E.; Ley, R. E.; Lozupone, C. A.; McDonald, D.; Muegge, B. D.;

810 Pirrung, M.; Reeder, J.; Sevinsky, J. R.; Tumbaugh, P. J.; Walters, W. A.; Widmann, J.;

811 Yatsunenko, T.; Zaneveld, J.; Knight, R. QIIME allows analysis of high-throughput

812 community sequencing data. Nature Methods 2010, 7 (5), 335-336. 
814 (33) Fish, J. A.; Chai B.; Wang, Q.; Sun, Y.; Brown, C.T.; Tiedje, J.M.; Cole, J.R. FunGene:

815 the Functional Gene Pipeline and Repository. Front. Microbiol. 2013, 4:291.

816

817 (34) Hoffman, GE, Schadt, EE. variancePartition: interpreting drivers of variation in complex 818 gene expression studies. BMC Bioinformatics. 2016; 17(1):483

819

820

(35) Shannon, P, Markiel, A, Ozier, O, Baliga, NS, Wang, JT, Ramage, D, Amin, N,

821 Schwikowski, B, Ideker, T. Cytoscape: a software environment for integrated models of 822 biomolecular interaction networks. Genome Res. 2003, 13(11):2498-504.

823

824

(36) Zhang, S.-Y.; Zhao, F.-J.; Sun, G.-X.; Su, J.-Q.; Yang, X.-R.; Li, H.; Zhu, Y.-G.

825 Diversity and abundance of arsenic biotransformation genes in paddy soils from southern 826 China. Environ. Sci. Technol. 2015, 49 (7), 4138-4146.

827

828 (37) Reid, M. C.; Maillard, J.; Bagnoud, A.; Falquet, L.; Phu Le Vo; Bernier-Latmani, R. 829 Arsenic Methylation Dynamics in a Rice Paddy Soil Anaerobic Enrichment Culture. Environ. Sci. Technol. 2017, 51 (18), 10546-10554.

831

832 (38) Xiao, K.-Q.; Li, L.-G.; Ma, L.-P.; Zhang, S.-Y.; Bao, P.; Zhang, T.; Zhu, Y.-G.

833 Metagenomic analysis revealed highly diverse microbial arsenic metabolism genes in paddy soils with low-arsenic contents. Environ. Pollut. 2016, 211, 1-8. 
836 (39) Nookongbut, P.; Kantachote, D.; Megharaj, M. Arsenic contamination in areas

837 surrounding minesand selection of potential As-resistant purple nonsulfur bacteria for use in

838 bioremediation based on their detoxification mechanism. Ann Microbiol. 2016, 66, 1419.

839

840 (40) Oda, Y.; Larimer, F.W.; Chain, P.S.; Malfatti, S.; Shin, M.V.; Vergez, L.M.; Hauser, L.;

841 Land, M.L.; Braatsch, S.; Beatty, JT.; Pelletier, D.A.; Schaefer, A.L.; Harwood, C.S.;

842 Multiple genome sequences reveal adaptations of a phototrophic bacterium to sediment

843 microenvironments. Proc Natl Acad Sci U S A. 2008. 105(47), 18543-18548.

844

845 (41) Lo, K.J.; Lin, S.S.; Lu, CW, Kuo, CH, Liu, CT. Whole-genome sequencing and 846 comparative analysis of two plant-associated strains of Rhodopseudomonas palustris (PS3 847 and YSC3). Sci Rep. 2018. 8(1),12769.

848

849 (42) Rayyan, A.; Meyer, T.; Kyndt, J.; Draft Whole-Genome Sequence of the Purple

850 Photosynthetic Bacterium Rhodopseudomonas palustris XCP. Microbiol Resour Announc.

851 2018. 7(4). pii: e00855-18.

852

853 (43) Kulichevskaya, IS.; Danilova, O.V.; Tereshina, V.M.; Kevbrin, V.V.; Dedysh, S.N.;

854 Descriptions of Roseiarcus fermentans gen. nov., sp. nov., a bacteriochlorophyll a-

855 containing fermentative bacterium related phylogenetically to alphaproteobacterial

856 methanotrophs, and of the family Roseiarcaceae fam. nov. Int J Syst Evol Microbiol. 2014. 857 64(Pt 8), 2558-2565. 
859 (44) Jiao, Y.; Kappler, A.; Croal, L.R.; Newman, D.K.; Isolation and characterization of a 860 genetically tractable photoautotrophic Fe(II)-oxidizing bacterium, Rhodopseudomonas

861 palustris strain TIE-1. Appl Environ Microbiol. 2005. 71(8), 4487-96.

862

863 (45) Jiao, Y.; Newman, D.K.; The pio operon is essential for phototrophic Fe(II) oxidation in 864 Rhodopseudomonas palustris TIE-1. J Bacteriol. 2007. 189(5), 1765-1773.

865

866

(46) Hedrich, S.; Schlömann, M.; Johnson, D.B.; The iron-oxidizing proteobacteria.

Microbiology. 2011. 157(Pt 6), 1551-64.

868

869 (47) Lovley, D.R.; Giovannoni, S.J.; White, D.C.; Champine, J.E.; Phillips, E.J.; Gorby, 870 Y.A.; Goodwin, S. Geobacter metallireducens gen. nov. sp. nov., a microorganism capable

871 of coupling the complete oxidation of organic compounds to the reduction of iron and other 872 metals. Arch Microbiol. 1993.159(4):336-444.

873

874 (48) Mahadevan, R.; Bond, D.R.; Butler, J.E.; Esteve-Nuñez, A.; Coppi, M.V.; Palsson, B.O.; 875 Schilling, C.H.; Lovley, D.R.; Characterization of metabolism in the Fe(III)-reducing 876 organism Geobacter sulfurreducens by constraint-based modeling. Appl Environ Microbiol. 877 2006. 72(2), 1558-68.

878

879 (49) Coby, A.J.; Picardal, F.; Shelobolina, E.; Xu, H.; Roden, E.E. Repeated anaerobic 880 microbial redox cycling of iron. Appl Environ Microbiol. 2011. 77(17), 6036-6042. 
882 (50) Emerson, D.; Weiss, J.V.; Megonigal, J.P.; Iron-oxidizing bacteria are associated with 883 ferric hydroxide precipitates (Fe-plaque) on the roots of wetland plants. Appl Environ 884 Microbiol. 1999. 65(6), 2758-2761.

885

886

(51) Kuramata, M.; Sakakibara, F.; Kataoka, R.; Abe, T.; Asano, M.; Baba, K.; Takagi, K.;

887

Ishikawa, S. Arsenic biotransformation by Streptomyces sp. isolated from rice rhizosphere.

Environ. Microbiol. 2015, 17 (6), 1897-1909.

889

890

(52) Kludze, H.; Delaune, R.; Patrick, W. Aerenchyma Formation and Methane and Oxygen891

Exchange in Rice. Soil Sci. Soc. Am. J. 1993, 57 (2), 386-391.

892

893

(53) York, L.M.; Carminati, A.; Mooney, S.J.; Ritz, K.; Bennett, M.J. The holistic

894

rhizosphere: integrating zones, processes, and semantics in the soil influenced by roots. $J$.

895

Exp. Bot. 2016, 67 (12), 3629-3643.

896

897

(54) Park, S. G.; Butcher, D. J. Investigation of the primary interactions between arsenic

898

species and thiols via electrospray ionization tandem mass spectrometry. Microchem. J. 2010,

899

95, 57-66.

900

901 (55) Carey, A. M.; Norton, G. J.; Deacon, C.; Scheckel, K. G.; Lombi, E.; Punshon, T.;

902 Guerinot, M. L.; Lanzirotti, A.; Newville, M.; Choi, Y.; Price, A. H.; Meharg, A. A. Phloem 903 transport of arsenic species from flag leaf to grain during grain filling. New Phytol. 2011,

904 $192,87-98$.

905

906 (56) Gu, Y.; Van Nostrand, J. D.; Wu, L.; He, Z.; Qin, Y.; Zhao, F.-J.; Zhou, J. Bacterial 
907

908

909

910

911

912

913

914

915

916

917

918

919

920

921

922

923

924

925

926

927

928

929

930

931

community and arsenic functional genes diversity in arsenic contaminated soils from different geographic locations. PLoS One 2017, 12 (5), e 0176696.

(57) Wang, P.-P.; Sun, G.-X.; Zhu, Y.-G. Identification and characterization of arsenite methyltransferase from an archaeon, Methanosarcina acetivorans C2A. Environ. Sci.

Technol. 2014, 48 (21), 12706-12713.

(58) Wang, P.-P.; Bao, P.; Sun, G.-X. Identification and catalytic residues of the arsenite methyltransferase from a sulfate-reducing bacterium, Clostridium sp. BXM. FEMS Microbiology Letters 2015, 362 (1), 1-8.

(59) Kuramata, M.; Sakakibara, F.; Kataoka, R.; Abe, T.; Asano, M.; Baba, K.; Takagi, K.; Ishikawa, S. Arsenic biotransformation by Streptomyces sp. isolated from rice rhizosphere. Environ Microbiol. 2015. 17(6), 1897-1909.

(60) Zhang, J.; Cao, T.; Tang, Z.; Shen, Q.; Rosen, B. P.; Zhao, F.-J. Arsenic methylation and volatilization by arsenite S-adenosylmethionine methyltransferase in Pseudomonas alcaligenes NBRC14159. Appl. Environ. Microbiol. 2015, 81 (8), 2852-2860.

(61) Huang, K.; Chen, C.; Zhang, J.; Tang, Z.; Shen, Q.; Rosen, B. P.; Zhao, F.-J. Efficient Arsenic Methylation and Volatilization Mediated by a Novel Bacterium from an ArsenicContaminated Paddy Soil. Environ. Sci. Technol. 2016, 50 (12), 6389-6396.

(62) Lu, H.; Chen, J.; Jia, Y.; Cai, M.; Lee, PK.H. Transcriptomic Responses of the Interactions between Clostridium cellulovorans $743 B$ and Rhodopseudomonas palustris 
932 CGA009 in a Cellulose-Grown Coculture for Enhanced Hydrogen Production. Appl Environ 933 Microbiol. 2016. 82(15), 4546-4559.

934

935 (63) Guan, X.; Yan, X.; Li, Y.; Jiang, B.; Luo, X.; Chi, X. Diversity and arsenic-tolerance 936 potential of bacterial communities from soil and sediments along a gold tailing contamination 937 gradient. Can J Microbiol. 2017. 63(9), 788-805.

938

939

(64) Mu, Y, Zhou, L, Zeng, XC, Liu, L, Pan, Y, Chen X, Wang J, Li S, Li WJ, Wang Y.

940 Arsenicitalea aurantiaca gen. nov., sp. nov., a new member of the family

941 Hyphomicrobiaceae, isolated from high-arsenic sediment. Int J Syst Evol Microbiol. 2016

$942 \quad 66(12), 5478-5484$.

943

944 (65) Limmer, M.A.; Wise, P.; Dykes, G.E.; Seyfferth, A.L. Silicon decreases dimethylarsinic 945 acid concentration in rice grain and mitigates straighthead disorder. Environmental science \& 946 technology 2018. $52(8), 4809-4816$.

947

948

949

950

951

952

953

954

955

956 
957 Table 1: Corresponding differential copy number patterns (see heatmap Figure 4a \& 4b)

958 identified for 16S rRNA OTUs and arsM gene OTUs in planted versus unplanted and

959 manured versus non-manured pairwise comparisons. Group-I = significant increase in

960 unplanted soil, Group-II = significant increase in planted soil, Group-III = significant

961 increase in manured soil, Group-IV = significant increase in non-manured soil, ** highest, *

962 second highest (if applicable) correlation to arsM OTUs. In bold $>1 \%$ abundant genera,

963 increase $=$ increase in copy number

\begin{tabular}{|c|c|c|}
\hline \multirow{2}{*}{ Group } & \multicolumn{2}{|c|}{ Bacterial 16S rRNA OTUs } \\
\hline & Phylum level & Genus level \\
\hline \multirow{4}{*}{ I } & Acidobacteria & $\underline{\text { Acidobacteria GP1 sp.** }}$ \\
\hline & Chloroflexi & Dehalogenimonas sp. \\
\hline & Cyanobacteria & Cryptomonadaceae sp. \\
\hline & Verrumicrobia & Alterococcus \\
\hline II & Firmicutes & Tumebacillus $^{*}$, Clostridium $^{* * 32}$, Desulfotomaculum \\
\hline \multirow{5}{*}{ III } & Acidobacteria & Geothrix \\
\hline & Actinobacteria & Aeromirobium, Georgenia, Thermobifida, Patulibacter, Cellulomonadaceae sp. \\
\hline & $\begin{array}{l}\text { Bacteroidetes } \\
\text { Cyanobacteria }\end{array}$ & $\begin{array}{l}\text { Paludibacter, Flavobacterim, Muricauda, Chitonophaga, Parasegetibacter, Algoriphagus, } \\
\text { Dyadobacter } \\
\text { Cyanobacteria GpIV sp. Bacillariophyta sp. }\end{array}$ \\
\hline & $\underline{\text { Firmicutes }}$ & $\begin{array}{l}\text { Geobacillus, Ammoniphilus, Brevibacillus, Cohnella, Paenibacillus, Thermobacillus, } \\
\text { Paenisporosarcina, Sporosarcina, Planifilum, Thermoactinomyces, Dehalobacter, } \\
\text { Thermoflavimicrobium, Oxobacter, Alkalibacter, Desulfitobacterium, Papillibacter, Halocella, } \\
\text { Lutispora, Anoxybacillus, Ocenobacillus, Ureibacillus, Desmospora, Garciella, } \\
\text { Parasporobacterium, Desulfosporosinus, Sporobacter, Dethibacter, Tepianaerobacter }\end{array}$ \\
\hline & $\begin{array}{l}\text { Proteobacteria } \\
\text { Verrumicrobia }\end{array}$ & $\begin{array}{l}\text { Aquabacterium, Cellvibrio, Thermomonas, Brevundimonas, Beijerinckia, Bosea, Devosia*, } \\
\text { Kaistia, Rhizobium, Xanthobacter, Paracoccus, Azospirillum, Magnetospirillum, Rickettsia, } \\
\text { Novosphingobium, Sphingobium, Sphingopyxis, Sphingosinicella, Achromobacter, Ralstonia, } \\
\text { Hydrogenophaga, Herbaspirillum, Herminiimonas, Methylophilus, Methylovorus, Aquaspirillum } \\
\text { Azoarcus, Shinella, Desulfocapsa, Geobacter, Rheinheimera, Halomonas, Pseudomonas }{ }^{33}, \\
\text { Pseudoxanthomonas } \\
\text { Luteolibacter }{ }^{* *}, \text { Verrucomicrobiaceae sp., Optutaceaesp }\end{array}$ \\
\hline \multirow{5}{*}{ IV } & Acidobacteria & Acidobacteria Gp25**, Gp22, Gp11, Gp5 sp. \\
\hline & Bacteroidetes & Bacteroides, $\underline{\text { Terrimonas } * \text {, Prevotellaceae } s p}$ : \\
\hline & Firmicutes & Tepidibacter \\
\hline & Cyanobacteria & Cyanobacteria_GpXI sp., Streptophyta sp. \\
\hline & Proteobacteria & Phaselicystis, Methylosarcina, Elioraea sp., Sinobacteraceae sp. \\
\hline
\end{tabular}


964 Table2: Annotation of representative arsM OTUs via Blastn against bacterial genomes using

965 1e-06 as cutoff for significance. The table shows the percentage of all sequences in each

966 group with best match against each genome: 1) all 2680 ars $M$ OTUs in the final filtered OTU

967 table, 2) the 347 arsM OTU's with identified significant changes in copy number, G1= 29

968 OTUs increased in unplanted soil, G2=32 OTUs increased in planted soil, G3=256 OTUs

969 increased in manured soil, G4= 57 OTUs significant increase in non-manured soil.

\begin{tabular}{|c|c|c|c|c|c|c|}
\hline blastn, genomes, top hit & $\begin{array}{c}\text { All } \\
\operatorname{ars} M\end{array}$ & $\begin{array}{l}\text { Sig. } \\
\text { ars }\end{array}$ & G1 & G2 & G3 & G4 \\
\hline Rhodopseudomonas palustris TIE-1 & 7.9 & 23.3 & 3.4 & 9.4 & 28.9 & 15.8 \\
\hline Rhodopseudomonas palustris BisB5 & 6.7 & 5.6 & 41.4 & 0.0 & 2.0 & 7.0 \\
\hline Roseiarcus fermentans strain DSM $24875^{*}$ & 6.2 & 31.8 & 0.0 & 3.1 & 45.7 & 1.8 \\
\hline Gemmatirosa kalamazoonesis strain KBS708 & 5.0 & 2.4 & 3.4 & 3.1 & 0.4 & 10.5 \\
\hline Rhodopseudomonas palustris strain YSC3 & 3.5 & 1.6 & 10.3 & 0.0 & 0.4 & 3.5 \\
\hline Streptomyces zinciresistens $K 42$ & 3.3 & 1.1 & 0.0 & 3.1 & 0.8 & 1.8 \\
\hline Thiobacillus denitrificans DSM 12475 & 3.2 & 0.5 & 0.0 & 0.0 & 0.4 & 1.8 \\
\hline Rhodopseudomonas palustris strain $X C P$ & 2.6 & 1.6 & 3.4 & 0.0 & 1.6 & 1.8 \\
\hline Blastopirellula marina DSM 3645 & 1.6 & 0.8 & 0.0 & 6.3 & 0.4 & 0.0 \\
\hline Rhodoplanes roseus strain DSM 5909 & 1.6 & 1.6 & 0.0 & 0.0 & 1.6 & 3.5 \\
\hline Rhodopseudomonas palustris HaA2 & 1.5 & 1.6 & 0.0 & 0.0 & 1.2 & 5.3 \\
\hline Rhodopseudomonas pentothenatexigens & 1.2 & 1.1 & 0.0 & 3.1 & 0.0 & 5.3 \\
\hline Thioalbus denitrificans strain DSM 26407 & 1.1 & 1.9 & 0.0 & 0.0 & 2.7 & 0.0 \\
\hline Intrasporangium chromatireducens Q5-1 & 1.0 & 0.5 & 0.0 & 3.1 & 0.4 & 0.0 \\
\hline Rhodomicrobium udaipurense JA643 & 0.9 & 0.8 & 0.0 & 0.0 & 1.2 & 0.0 \\
\hline Rhodoplanes elegans strain DSM 11907 & 0.8 & 0.8 & 3.4 & 0.0 & 0.0 & 3.5 \\
\hline Streptomyces aurantiacus JA 4570 & 0.7 & 1.6 & 6.9 & 12.5 & 0.0 & 0.0 \\
\hline Rhodopseudomonas palustris CGA009 & 0.7 & 0.8 & 0.0 & 3.1 & 0.8 & 0.0 \\
\hline Nocardioides sp. JS614 & 0.7 & 0.5 & 0.0 & 0.0 & 0.0 & 3.5 \\
\hline Acidobacteriaceae bacterium SbAl & 0.6 & 0.5 & 0.0 & 0.0 & 0.4 & 1.8 \\
\hline Stackebrandtia nassauensis DSM 44728 & 0.4 & 0.5 & 0.0 & 0.0 & 0.0 & 3.5 \\
\hline Halobacterium sp. DL1 & 0.4 & 0.5 & 0.0 & 0.0 & 0.4 & 1.8 \\
\hline Streptomyces sp. Root 1310 & 0.4 & 0.5 & 0.0 & 0.0 & 0.4 & 1.8 \\
\hline Methanoculleus taiwanensis strain CYW4 & 0.4 & 0.5 & 0.0 & 0.0 & 0.0 & 3.5 \\
\hline Rhodopseudomonas palustris $D X-1$ & 0.3 & 0.5 & 0.0 & 3.1 & 0.4 & 0.0 \\
\hline Thiocapsa sp. KS1 & 0.3 & 0.5 & 6.9 & 0.0 & 0.0 & 0.0 \\
\hline Planctomyces sp. SH-PL62 & 0.2 & 0.5 & 0.0 & 6.3 & 0.0 & 0.0 \\
\hline Microlunatus phosphovorus NM-1 & 0.2 & 0.5 & 6.9 & 0.0 & 0.0 & 0.0 \\
\hline Telmatospirillum siberiense strain 26-4b1 & 0.1 & 0.5 & 0.0 & 6.3 & 0.0 & 0.0 \\
\hline matches to other genomes & 25.0 & 7.5 & 10.3 & 21.9 & 3.5 & 15.8 \\
\hline no genome match & 21.5 & 7.2 & 3.4 & 15.6 & 6.6 & 7.0 \\
\hline
\end{tabular}


972

973

974

975

976

977

978

979

980

981

982

983

984

985

986

987

988

989

990

991

992

993

994

995

996

\section{Legends to figures}

Figure 1. Box plot of soil solution arsenic speciation and relative soil arsM and 16S rRNA copy number in replicated microcosms (experiment2). The error bars are standard error of means as calculated in the GLM analysis. Paired lines above bars show identified significant manure (2 larger lines) and plant effect (2 smaller lines), with '*', ‘**', ‘***' above indicating $\mathrm{p}<0.05, \mathrm{p}<0.01,{ }^{* * *} \mathrm{p}<0.001$, respectively and ' + ' indicating significant interaction effect of manure and plants (GLM, Minitab). The associated probabilities are reported in Table S3.

Figure 2. Heatmap showing normalized counts of OTUs with significant differences in copy number ( $\mathrm{p}<0.05$ and absolute $\log 2 \mathrm{FC}>1$, experiment 2). (A) level $616 \mathrm{~S}$ rRNA; (B) ars $M$ gene OTUs. Darker blue indicates greater normalized count. Group-I = significantly higher copy number in unplanted soil, Group-II = significantly higher copy number in planted soil, Group-III = significantly higher copy number in manured soil, Group-IV = significantly higher copy number in non-manured soil. A: Acidobacteria, Ac: Actinobacteria, B: Bacteroidetes, Ch: Chloroflexi, Cy: Cyanobacteria, F: Firmicutes, P: Proteobacteria and V: Verrumicrobia.

Figure 3. Variance partition analysis plot for genus level 16S rRNA OTUs with significant differences in copy number in response to planting (heatmap, Group I and II). A: Violin plot, showing the median and variance of the contribution of manure treatment and planting across all OTUs, B: Corresponding bar chart for each OTU. 
997 Figure 4. Network analysis of genus level 16S rRNA OTUs that show significant differences

998 in copy number in response to planting. A, B, C, D= selected level 6 OTUs (genera) with

999 significantly higher copy number in non-planted soil (heatmap, Group I), A=

1000 AcidobacteriaGP1, B=Dehalogenimonas, $\mathrm{C}=$ Cryptomonadaceae, $\mathrm{D}=$ Alterococcus. $\mathrm{E}, \mathrm{F}, \mathrm{G}=$ 1001 selected level 6 OTUs with significantly higher copy number in planted soil (heatmap,

1002 GroupII), $\mathrm{E}=$ Tumebacillus, $\mathrm{F}=$ Clostridium, $\mathrm{G}=$ Desulfomaculum. Missing samples in the 1003 network for Cryptomonadaceae (C) are samples with a copy number count of 0.

1004

1005

1006

1007

1008

1009

1010

1011

1012

1013

1014

1015

1016

1017

1018

1019

1020

1021 
$1023 \quad$ Figure1.
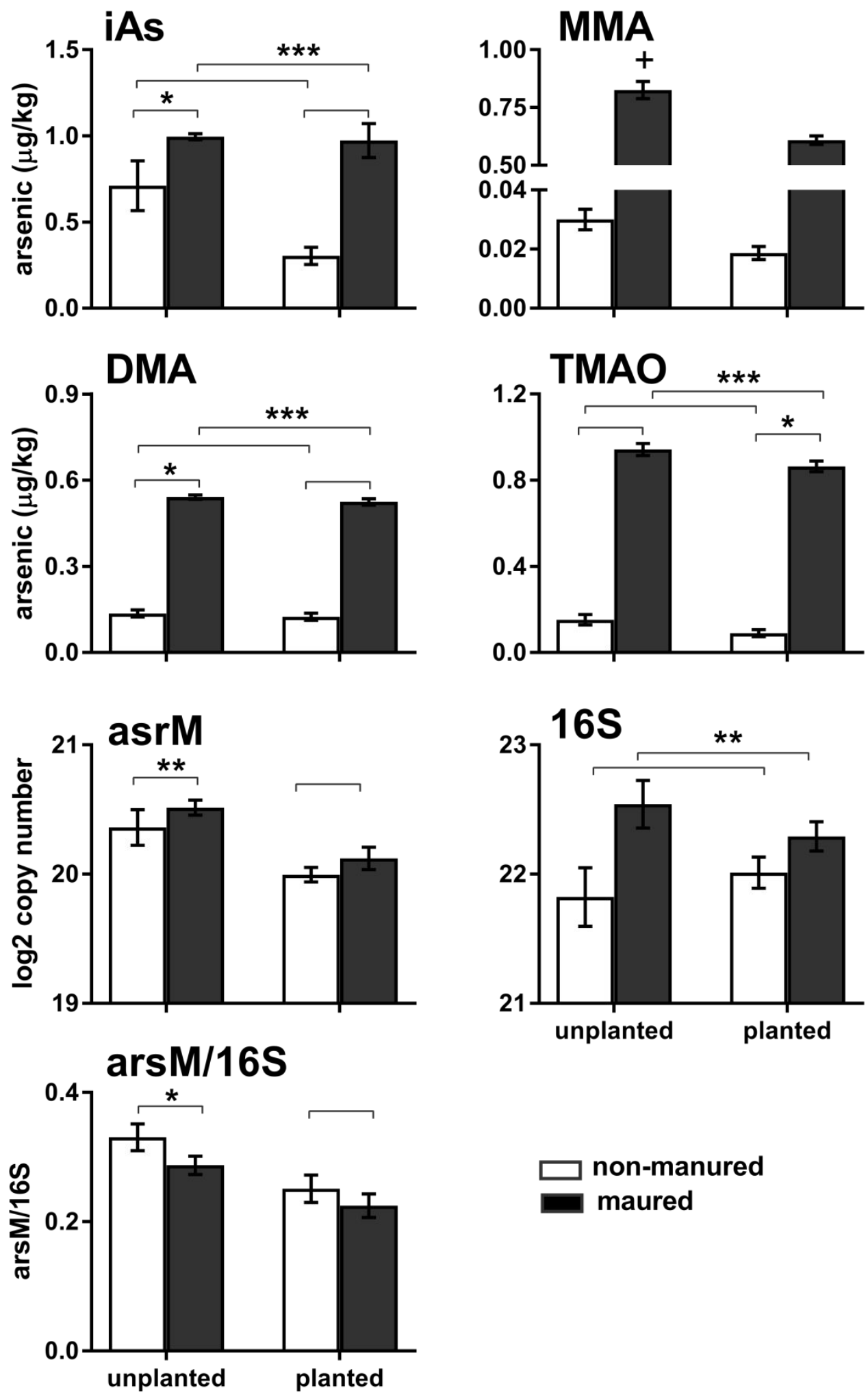
1026

1027 Figure 2.
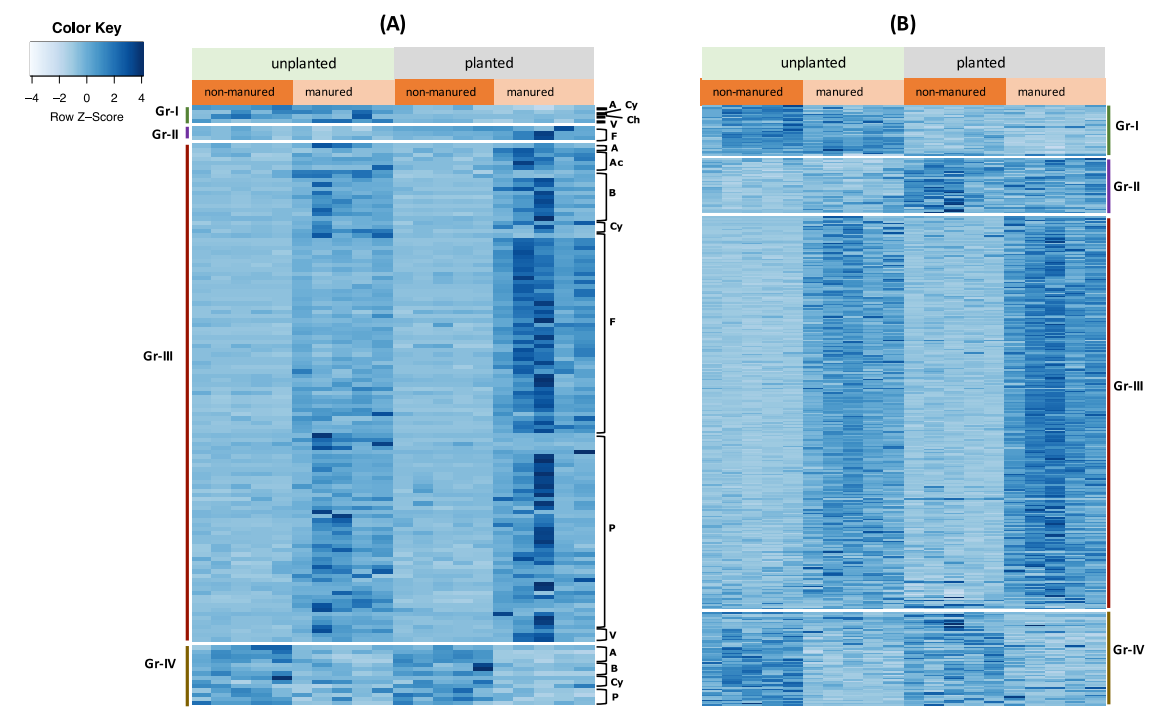

1028

1029

1030

1031

1032

1033

1034

1035

1036

1037

1038

1039

1040

1041

1042 
1043

$1044 \quad$ Figure 3.

A

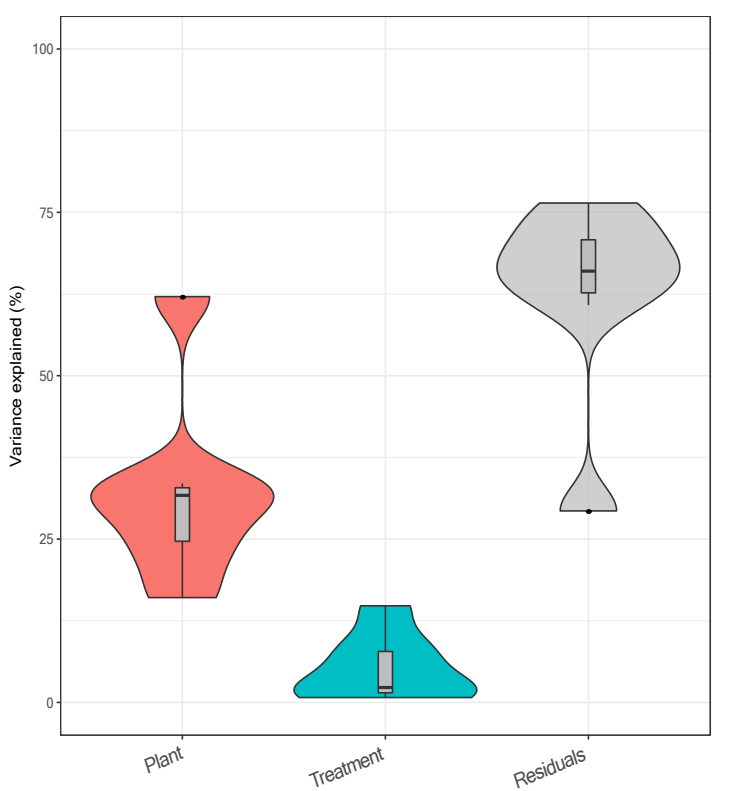

B

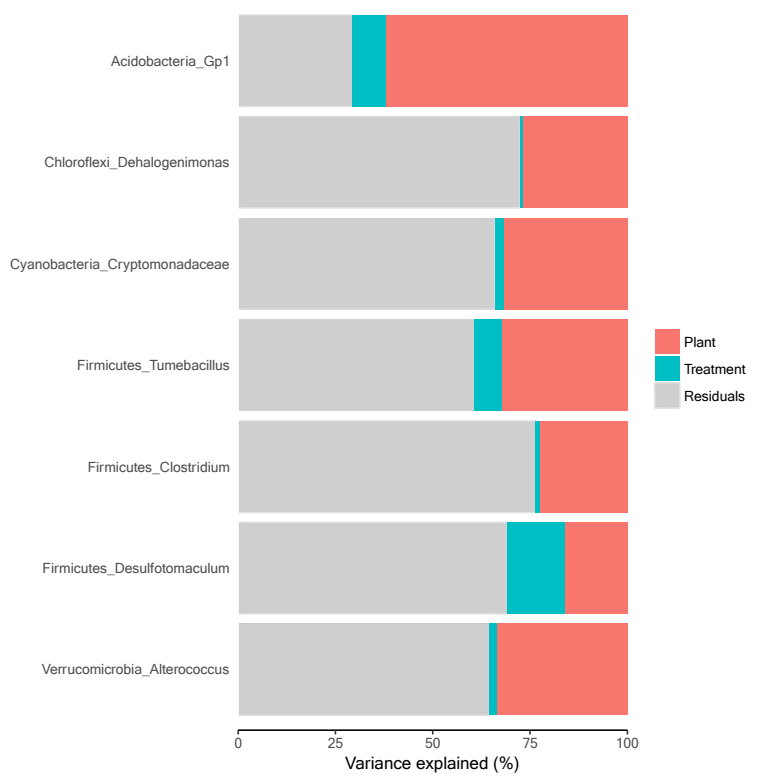

1045

1046

1047

1048

1049

1050

1051

1052

1053

1054

1055

1056

1057

1058

1059 
1060

$1061 \quad$ Figure 4.

A

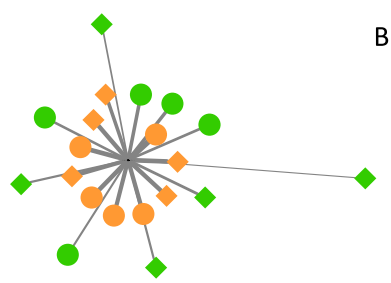

E

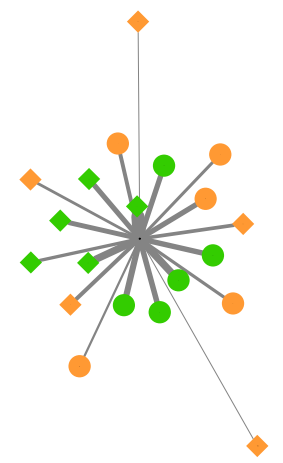

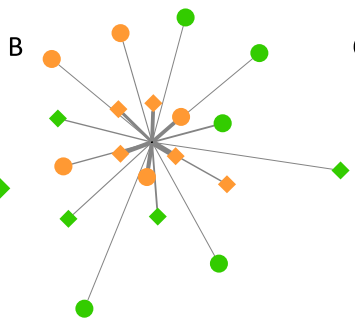

$\mathrm{F}$

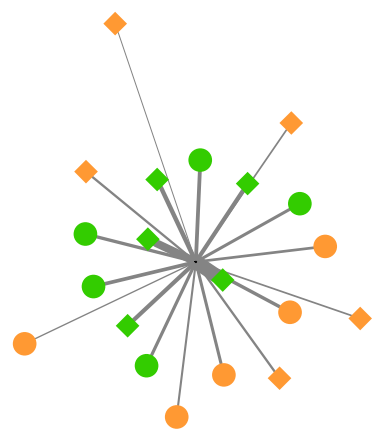

C

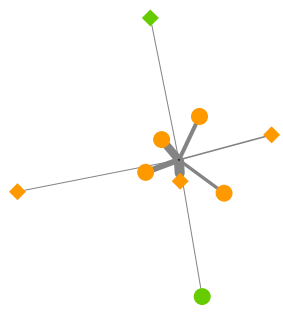

G

G

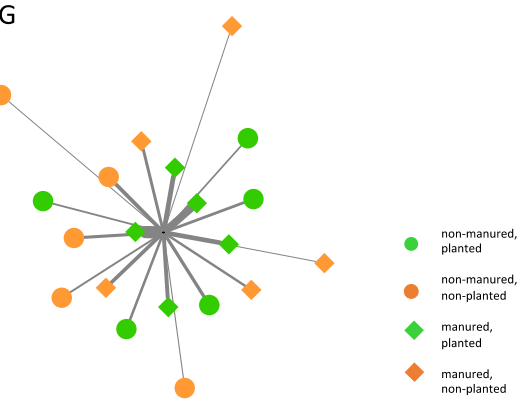

1062

1063 


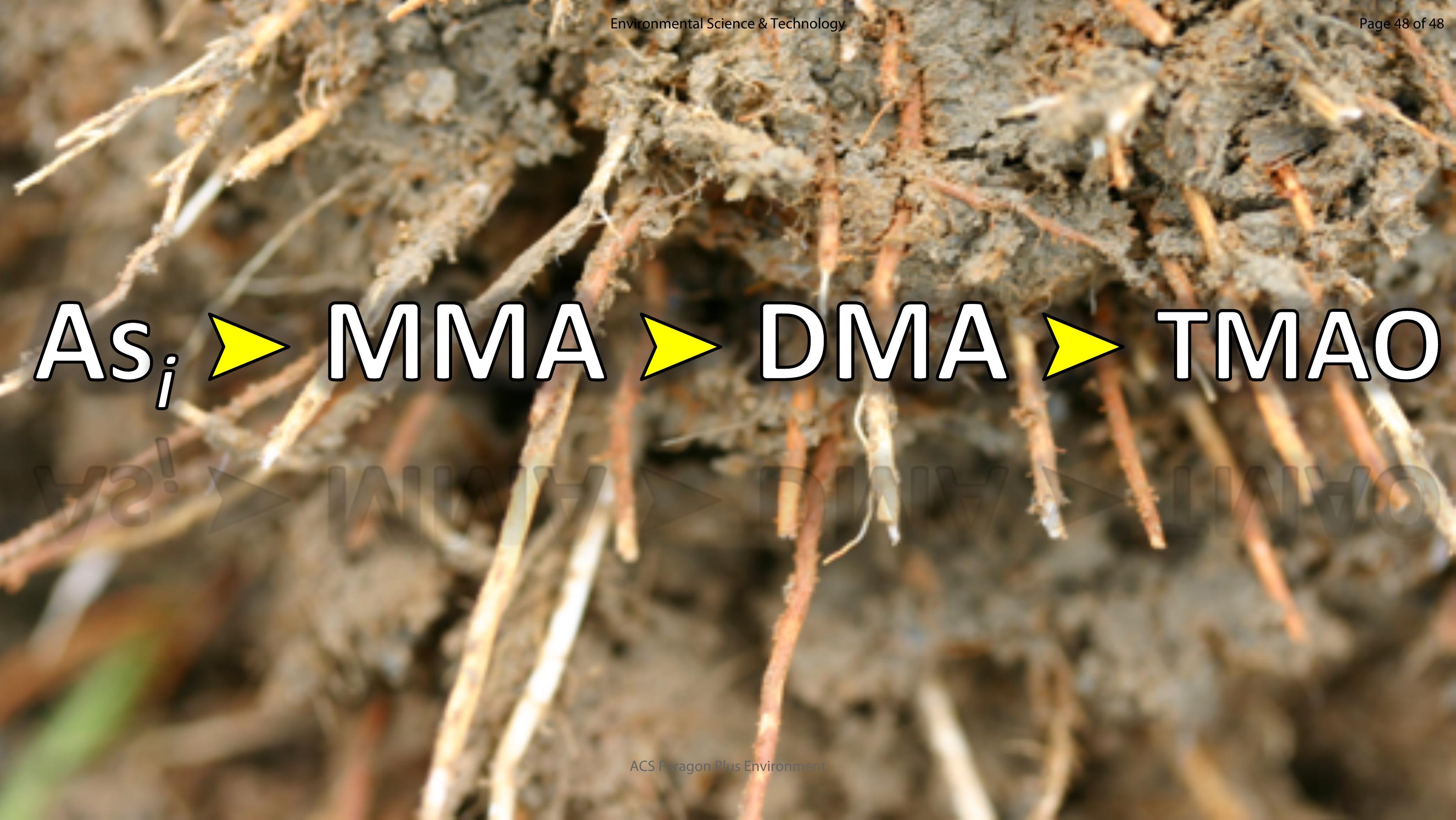

